\title{
Examining Deep Convective Cloud Evolution Using Total Lightning, WSR-88D, and GOES-14 Super Rapid Scan Datasets*
}

\author{
KRISTOPHER M. BEDKA \\ NASA Langley Research Center, Hampton, Virginia \\ CECILIA WANG \\ Science Systems and Applications, Inc., Hampton, Virginia \\ RyAN Rogers AND LAWRENCE D. CAREY \\ University of Alabama in Huntsville, Huntsville, Alabama
}

WAYNE FELTZ

Cooperative Institute for Meteorological Satellite Studies, University of Wisconsin-Madison, Madison, Wisconsin

JAN KANAK

Slovak Hydrometeorological Institute, Bratislava, Slovakia

(Manuscript received 12 June 2014, in final form 4 December 2014)

\begin{abstract}
The Geostationary Operational Environmental Satellite-14 (GOES-14) Imager operated in 1-min Super Rapid Scan Operations for GOES-R (SRSOR) mode during summer and fall of 2012 to emulate the high temporal resolution sampling of the GOES-R Advanced Baseline Imager (ABI). The current GOES operational scan interval is $15-30 \mathrm{~min}$, which is too coarse to capture details important for severe convective storm forecasting including 1) when indicators of a severe storm such as rapid cloud-top cooling, overshooting tops, and above-anvil cirrus plumes first appear; 2) how satellite-observed cloud tops truly evolve over time; and 3) how satellite cloud-top observations compare with radar and lightning observations at high temporal resolution. In this paper, SRSOR data, radar, and lightning observations are used to analyze five convective storms, four of which were severe, to address these uncertainties. GOES cloud-top cooling, increased lightning flash rates, and peak precipitation echo tops often preceded severe weather, signaling rapid intensification of the storm updraft. Near the time of several severe hail or damaging wind events, GOES cloud-top temperatures and radar echo tops were warming rapidly, which indicated variability in the storm updraft that could have allowed the hail and wind gusts to reach the surface. Above-anvil cirrus plumes were another prominent indicator of impending severe weather. Detailed analysis of storms throughout the 2012 SRSOR period indicates that $57 \%$ of the plume-producing storms were severe and $85 \%$ of plumes from severe storms appeared before a severe weather report with an average lead time of $18 \mathrm{~min}, 9 \mathrm{~min}$ earlier than what would be observed by GOES operational scanning.
\end{abstract}

* Supplemental information related to this paper is available at the Journals Online website: http://dx.doi.org/10.1175/WAF-D-1400062.s1.

Corresponding author address: Kristopher Bedka, NASA Langley Research Center, Mail Stop 420, Hampton, VA 23681.

E-mail: kristopher.m.bedka@nasa.gov

\section{Introduction}

The Geostationary Operational Environmental Satellite14 (GOES-14) collected observations at 1-min time intervals during the Super Rapid Scan Operations for GOES-R (SRSOR) test that took place during much of the time period from 16 August to 31 October 2012 (Schmit et al. 2014). Prior to the 2012 SRSOR test, super 
rapid scan satellite imagery has proven to be useful during postlaunch science tests and other nonoperational periods (Schmit et al. 2014). Super rapid scan data are now increasingly being used in quantitative applications such as the derivation of atmospheric motion vectors, analysis of wildfires, convective initiation nowcasting, and identification of overshooting convective cloud tops (Schmit et al. 2014). These quantitative products can help efficiently extract value-added information from the large volume of data. Super rapid scan data are particularly useful for monitoring convection as storms evolve significantly on time scales shorter than the current GOES 15- to 30-min operational and 7.5-min rapid scanning frequencies (Dworak et al. 2012; Cintineo et al. 2013).

Several unique signatures have been identified within satellite imagery of severe convective storm tops. These signatures include rapid cloud-top cooling (Cintineo et al. 2013), overshooting tops [OTs; Dworak et al. (2012) and references therein], above-anvil cirrus plumes (Levizzani and Setvák 1996), the cold ring (Setvák et al. 2010), and enhanced $U$ or enhanced $V$ satellite-observed signature (McCann 1983; Brunner et al. 2007). These signatures typically precede severe weather reports, but the lead time and how they relate to severe weather indicators derived from ground-based radar and lightning detection datasets remains unclear. In this paper, we seek to better understand the relationships between high temporal resolution satellite, lightning, and radar observations and derived products through detailed analyses of several deep convective storms.

Satellite, radar, and lightning observations depict different properties of convective storms; thus, a better understanding of their relative value for severe storm nowcasting can be achieved from a time-synchronized fusion of these datasets. Satellite imagers detect reflected sunlight and emission of heat (i.e., temperature) by cloud tops and spatial patterns and temporal trends in these parameters can be used to infer in-cloud and cloud-top dynamics. The OT region is typically very cold relative to the surrounding cirrus anvil as a result of adiabatic cooling in the storm updraft. As the OT penetrates through the anvil, it obstructs sunlight and produces a shadow on the surrounding anvil. The shadow length can be used to calculate the magnitude of OT penetration and estimate cloud-top height (Hasler et al. 1991). The presence of cirrus plumes above the anvils of some intense thunderstorms in satellite data indicate that injection of ice through the local equilibrium level has occurred. In certain situations, above-anvil cirrus plumes can adjust to the ambient temperature of the stratosphere that is warmer than the primary anvil residing in the upper troposphere. This causes the plume to be anomalously warm, contributing to the formation of cold-ring and enhanced $U$ or enhanced $V$ signatures.
Weather radars observe convective storms in quasihorizontal slices and detect reflected radiation from precipitation hydrometeors that, in the case of Doppler radars, can also be used to estimate wind velocity. Weather radar data can be used to detect features such as precipitation cores, severe hail and wind, and storm rotation associated with mesocyclones and tornadoes. The NOAA Weather Surveillance Radar-1988 Doppler (WSR-88D) network provides volume scans every $5 \mathrm{~min}$ and serves as the primary dataset used to determine storm severity in National Weather Service operations.

Three-dimensional lightning mapping arrays detect total lightning [cloud to ground (CG) and in cloud (IC)] by locating individual radiation sources within a convective storm that can subsequently be grouped into "flashes." Lightning flashes are typically initiated in close proximity to the updraft region but extensive flashes can travel $+100 \mathrm{~km}$ from their source region (Bruning and MacGorman 2013). A total lightning increase is noted to be an early indicator of a strengthening updraft and especially sharp total lightning increases (i.e., "jumps") are a demonstrated severe weather precursor (Schultz et al. 2009, 2011). Total lightning data are becoming increasingly available at $1 \mathrm{~s}$ or better precision from regional lightning mapping arrays such as the Northern Alabama Lightning Mapping Array (NALMA; Goodman et al. 2005) and new commercially available products such as the Earth Networks Total Lightning Network (ENTLN). These total lightning datasets serve as a proxy for the GOES-R Geostationary Lightning Mapper (GLM; Goodman et al. 2013). CG lightning is also detected by the Vaisala National Lightning Detection Network (NLDN), which provides near-uniform coverage of the continental United States (CONUS) and offshore waters (Orville 2008) at $1 \mathrm{~s}$ or better precision.

The GOES SRSOR dataset offers a unique opportunity to compare and better understand the relationships between satellite, radar, and total lightning data and their derived products. Studies such as this one help to introduce the operational forecasting community to the types of datasets and severe weather indicators that can be obtainable through GOES-R Advanced Baseline Imager (ABI) and GLM observations. In this paper, these datasets will be analyzed for five individual convective storms across the central and southeastern United States, four of which produced severe weather including 2.75-in.-diameter hail and a tornado ranked as a category 2 event on the enhanced Fujita scale (EF2). To the authors' knowledge, this type of quantitative study has never been done because of the limited availability of super rapid scan satellite and total lightning datasets. One severe and one nonsevere storm were located within the range of the NALMA, allowing for 


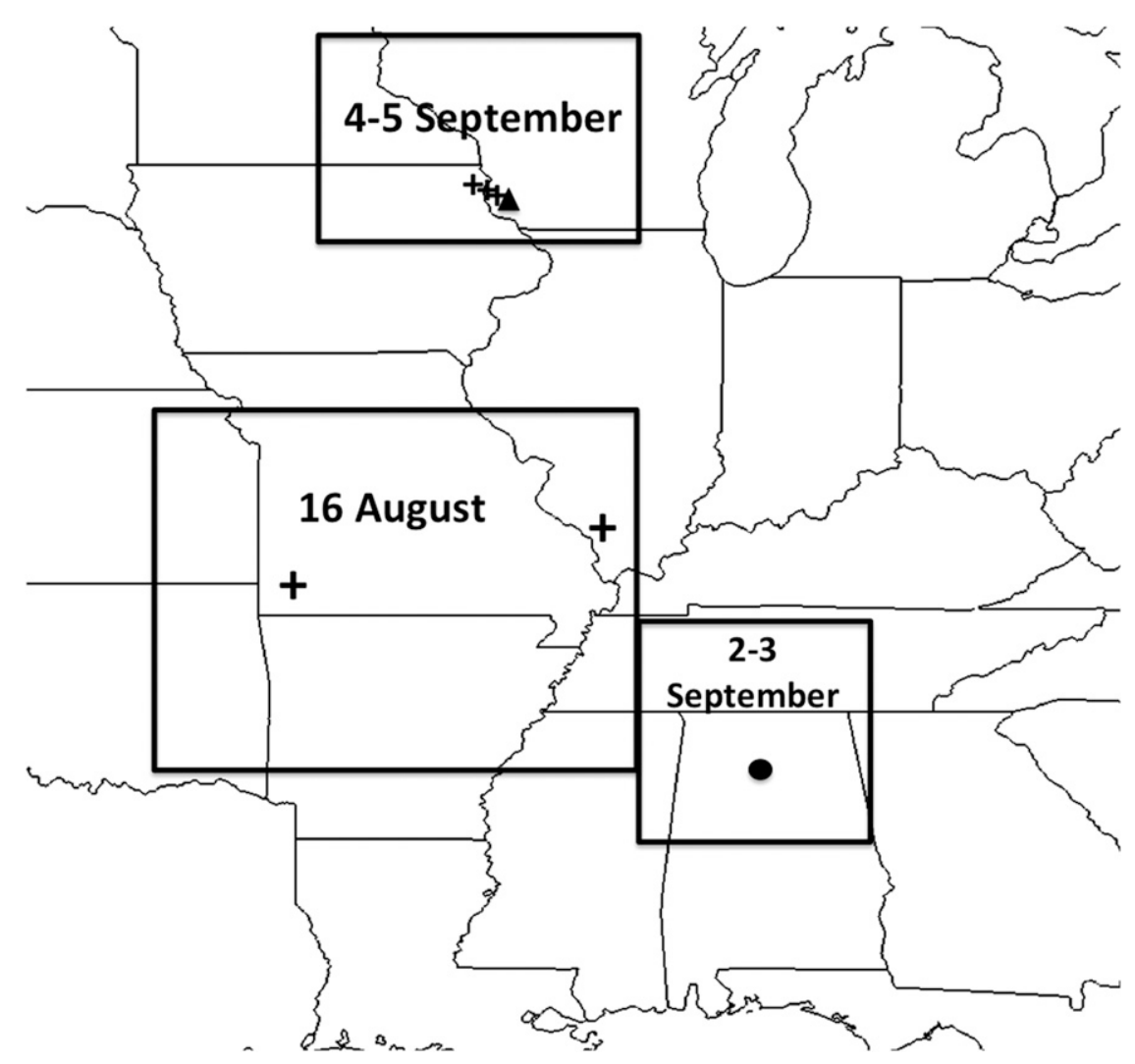

FIG. 1. Domains where deep convective storms were present for three 2012 GOES-14 SRSOR events. Five storms were monitored at 1-min resolution across these three events and the locations of severe weather reports associated with four of the storms are indicated with symbols. The plus signs, circle, and triangle indicate large hail, damaging wind, and tornado, respectively.

the collocation of the NLDN, ENTLN, and NALMA lightning datasets. This synthesis of lightning observations will demonstrate the characteristics of the ENTLN, a dataset that has not been extensively validated in the literature but will serve as the total lightning dataset for all five storms.

Several of these storms produced above-anvil cirrus plumes, prompting a more detailed analysis given that the plume-severe weather relationship has yet to be examined in detail or quantified in the literature. Visible channel images were examined for all storms occurring over the CONUS during the 2012 SRSOR period to identify plume-producing storms and the time of initial plume appearance. The time of plume appearance is compared with severe weather reports to determine the average lead time that could be provided by early recognition of the plume signature.

\section{Datasets}

Five individual convective storms occurring on 16 August, 2-3 September, and 4-5 September 2012 are analyzed in this paper. Figure 1 shows the domains where severe storms were concentrated during the three events and locations of severe weather reports from the five storms. For the five storms, the following datasets were analyzed at 1-min intervals: 1) GOES-14 10.7- $\mu \mathrm{m}$ IR brightness temperature (simply BT hereafter) and $0.65-\mu \mathrm{m}$ visible imagery, 2) objective GOES OT detection algorithm output, 3) total lightning flash detection data from the NALMA and/or ENTLN, and 4) CG lightning flash detection data from the NLDN. The OT height was estimated at 1-min intervals for two storms during 2-3 September. WSR-88D precipitation echo tops at multiple reflectivity thresholds and maximum expected size of hail (MESH) product output were also analyzed at 5-6-min intervals. $G O E S-14$ visible imagery was also analyzed for every storm that occurred over the CONUS during the 2012 SRSOR period to identify the presence of aboveanvil cirrus plumes [see Schmit et al. (2014) for details].

\section{a. GOES-14 SRSOR imagery}

Schmit et al. (2014) provide a full description of the 2012 GOES-14 SRSOR period, but a summary is provided below for background. The 2012 GOES-14 SRSOR schedule consisted of 26 images every $30 \mathrm{~min}$, 
with the exception of the 30-min gap every $3 \mathrm{~h}$ during full-disk scans. The SRSOR allows for more rapid imaging than the standard Rapid Scan Operations (RSO). While the SRSOR scans an area nominally each min, the RSO is only as fine as $5 \mathrm{~min}$ (and at times only 10 or $30 \mathrm{~min}$ ). These schedules both require a full disk to be imaged every $3 \mathrm{~h}$, which always left 30-min gaps during 2012 SRSOR. The GOES-R ABI will be able to routinely take images of $1000-\mathrm{km}^{2}$ regions at 30 -s intervals (Schmit et al. 2005). The SRSOR dataset provides the best proxy for the ABI mesoscale imaging frequency to date, though the SRSOR data are not truly representative of the ABI because the ABI will also offer improved spatial resolution (by a factor of 4), on-orbit calibration of all bands, improved bit depth, more spectral bands (by over a factor of 3), and improved image navigation and registration (Schmit et al. 2005). GOES-14 had a nadir position of $105^{\circ} \mathrm{W}$ for the cases studied in this paper. GOES-14 visible and BT data were acquired using the Man computer Interactive Data Access System-X (McIDAS-X) software package (Lazzara et al. 1999). These data were used as input into an objective OT detection algorithm (see section $2 \mathrm{~b}$ ) and are visualized using the McIDAS-V software package (Achtor et al. 2008). Animations of SRSOR visible and IR BT imagery are provided for the five storms described in this paper as part of the supplemental material for this paper available online.

\section{b. GOES-14 objective overshooting convective top detections}

GOES-14 SRSOR IR BTs were processed with an objective OT detection algorithm developed by the GOES-R Aviation Algorithm Working Group (Bedka et al. 2010). The goal of including these data in the study is to assess OT detection relationships with other datasets and examine algorithm performance in storms with frequent and/or persistent overshooting. This algorithm uses a combination of 1) BTs and their spatial gradients, 2) a tropopause temperature analysis from the NASA Modern-Era Retrospective Analysis for Research and Applications (MERRA; Rienecker et al. 2011), and 3) OT size and BT criteria derived through the analysis of 1-km MODIS and Advanced Very High Resolution Radiometer (AVHRR) imagery of OTs. The objective OT detection algorithm takes advantage of these characteristics by identifying clusters of pixels significantly $(\geq 6 \mathrm{~K})$ colder than the surrounding cirrus anvil cloud with a diameter consistent with commonly observed OTs (typically less than $15 \mathrm{~km}$ ). For a pixel to be considered an OT, the BT must be $\leq 217.5 \mathrm{~K}$ and is allowed to be up to $2.5 \mathrm{~K}$ warmer than the MERRA tropopause temperature, a threshold that is based on practical experience and allows for some error in the tropopause temperature and smoothing of the GOES BT induced by coarse spatial resolution. (See section $3 \mathrm{~d}$ for discussion on this topic.) The net result is a database of OT pixel detections at 1-min intervals for the five storms.

\section{c. Lightning datasets}

The NALMA is a very high frequency (VHF) threedimensional time-of-arrival (TOA) network consisting of 10 sensors dispersed across northern Alabama with a base station located at the National Space Science and Technology Center in Huntsville, Alabama. The network uses the precise time synchronization afforded by onboard GPS technology to independently compute the arrival time of electromagnetic radiation at each station. Data from six or more stations are then used to unambiguously locate VHF radiation sources in space and time. Individual VHF radiation sources are grouped into flashes via a flash-clustering algorithm designed for the NALMA network (McCaul et al. 2005, 2009). For the purposes of this study, we have only considered LMA flashes that contain eight or more radiation sources. This eliminates the inclusion of flashes consisting of only a few VHF radiation sources that are likely associated with noise rather than legitimate lightning processes.

The ENTLN is composed of 700 wideband lightning sensors covering much of the United States and over 40 countries (http://www.earthnetworks.com/Products/ TotalLightningNetwork.aspx). The ENTLN has unique sensor technology with a broad frequency range extending from $1 \mathrm{~Hz}$ to $12 \mathrm{MHz}$ and sophisticated waveform processing technology, allowing for accurate lightning location and differentiation between CG and IC lightning (Liu and Heckman 2010). We used quality controlled data directly from ENTLN and implemented a flash-clustering scheme, similar to what is outlined by Cummins et al. (1998) for NLDN data, which determines flashes from stroke and pulse information using temporal and spatial constraints. ENTLN flash location accuracy is estimated to be on the order of several hundred meters (S. Heckman 2013, personal communication). ENTLN data were available for all five storms in this paper and are used as the primary total lightning dataset for storms outside the NALMA domain.

The NLDN detects CG lightning strikes in real time with over 100 sensors across the CONUS (Orville 2008). The NLDN provides lightning flash detection efficiency near $95 \%$ and a flash location accuracy of $500 \mathrm{~m}$ or better during both day and night. The NLDN lightning flash detections have a temporal precision of 
$1 \mathrm{~s}$ that is comparable to the total lightning datasets described above.

\section{d. WSR-88D}

Precipitation echo top and MESH derived from WSR-88D were selected for analysis with satellite and lightning data because these fields were thought to correspond well with updraft intensity. Radar sites analyzed in this study include St. Louis and Springfield, Missouri, for the 16 August event; Huntsville, Alabama, for the 2-3 September event; and La Crosse, Wisconsin, for the $4-5$ September event. An echo top is the maximum height at which a given reflectivity threshold is observed by the WSR-88D. Echo tops from the 18.5-, 30-, and 40-dBZ reflectivity levels are analyzed for four of the five storms. The WSR-88D level-II raw volumetric data were unavailable for the Springfield radar; thus, the multireflectivity echo-top analysis could not be done for the Pierce City, Missouri, hail event. But level-III data files containing the 18.5-dBZ echo top via the Enhanced Echo Tops product were available for this case.

The WSR-88D hail detection algorithm (HDA) provides information regarding the probability of hail, probability of severe hail (POSH), and MESH (Witt et al. 1998). The HDA uses two weighting functions: one that weights reflectivity values and one that weights the heights of reflectivity values with respect to freezing level heights. Vertical integration of these weighting functions, which emphasize large reflectivity and subfreezing heights, yields the severe hail index (SHI). Both MESH and POSH are derived products from the SHI. The MESH data used in this study were produced within the Multi-Radar/Multi-Sensor (MRMS) framework (Cintineo et al. 2012). By using multiple radars, gaps in radar coverage because of issues such as terrain blockage, the "cone of silence," and the radar beam height exceeding the tops of clouds at far ranges may be mitigated. In addition, multiple radar estimates at any particular point can give a better final estimate.

\section{e. Severe weather report database}

Severe weather reports from the NOAA Storm Prediction Center (SPC) were used to identify the timing of severe weather produced by storms throughout the SRSOR period. The severe weather reports contain the date, time, and latitude-longitude coordinates of tornado, large hail ( $\geq 1 \mathrm{in}$; 1 in. $=2.5 \mathrm{~cm})$, or severe wind [ $\geq 50$ knots $\left.\left(\mathrm{kt} ; 1 \mathrm{kt}=0.51 \mathrm{~m} \mathrm{~s}^{-1}\right)\right]$ reports in addition to the hail diameter and estimated and/or observed wind speed. These reports are collected by NOAA NWS field offices across the United States and are reviewed by SPC to ensure their quality and validity.

\section{Methodology and caveats}

There are two sets of analyses included in this paper. The first analysis involves derivation of time series of the aforementioned datasets near the primary updraft region of five convective storms. This is done to develop a better understanding of how these datasets evolve throughout the developing and mature phases of the storm life cycle, with an emphasis on time periods near severe weather reports. The primary updraft region (referred to as the storm center) is defined by the location of minimum GOES IR BT. All other datasets are extracted at these locations and line plots throughout the time periods of interest are produced (see Fig. 4, described in greater detail below, for an example). Derivation of the height differential between the peak of the OT and the surrounding anvil cloud requires detailed analysis that is described below. The second analysis identifies above-anvil cirrus plume events using SRSOR visible channel imagery and determines the relationship of these events with SPC severe weather reports. A number of caveats associated with these analyses and underlying datasets are also explained.

\section{a. Storm cell time series analysis}

The five storms were selected for several reasons, including 1) they remained coherent for a relatively long time period (up to $\sim 1.5 \mathrm{~h}$ ) to provide meaningful time series, 2) they were located far enough $(>15 \mathrm{~km})$ from other storms so an accurate lightning flash time series could be derived, 3) they existed during (mostly) daylight hours so OTs and above-anvil cirrus plumes could be identified in visible imagery, and 4) the storms on 2 September were within $100 \mathrm{~km}$ of the NALMA center, providing a highly accurate total lightning time series that could be used to verify ENTLN trends. Four of the storms were severe but a fifth nonsevere storm was included to examine how the nonsevere storm evolved relative to the others.

SRSOR data were analyzed at 1-min intervals to identify the exact storm positions. The parallax-corrected location of the BT minimum represented the storm center in this analysis. As the BT minima can be challenging to identify at times, especially during periods of storm weakening, the satellite-based storm position was cross referenced with the center of clusters of ENTLN (16 August and 4-5 September events) or NALMA (2-3 September events) lightning flash detections to ensure the accuracy and temporal coherency of the storm center. The storm center coordinate, the minimum BT, and OT detection output were recorded as long as the storm remained coherent and independent of other nearby storms. The analysis began no earlier than 2315 UTC for 


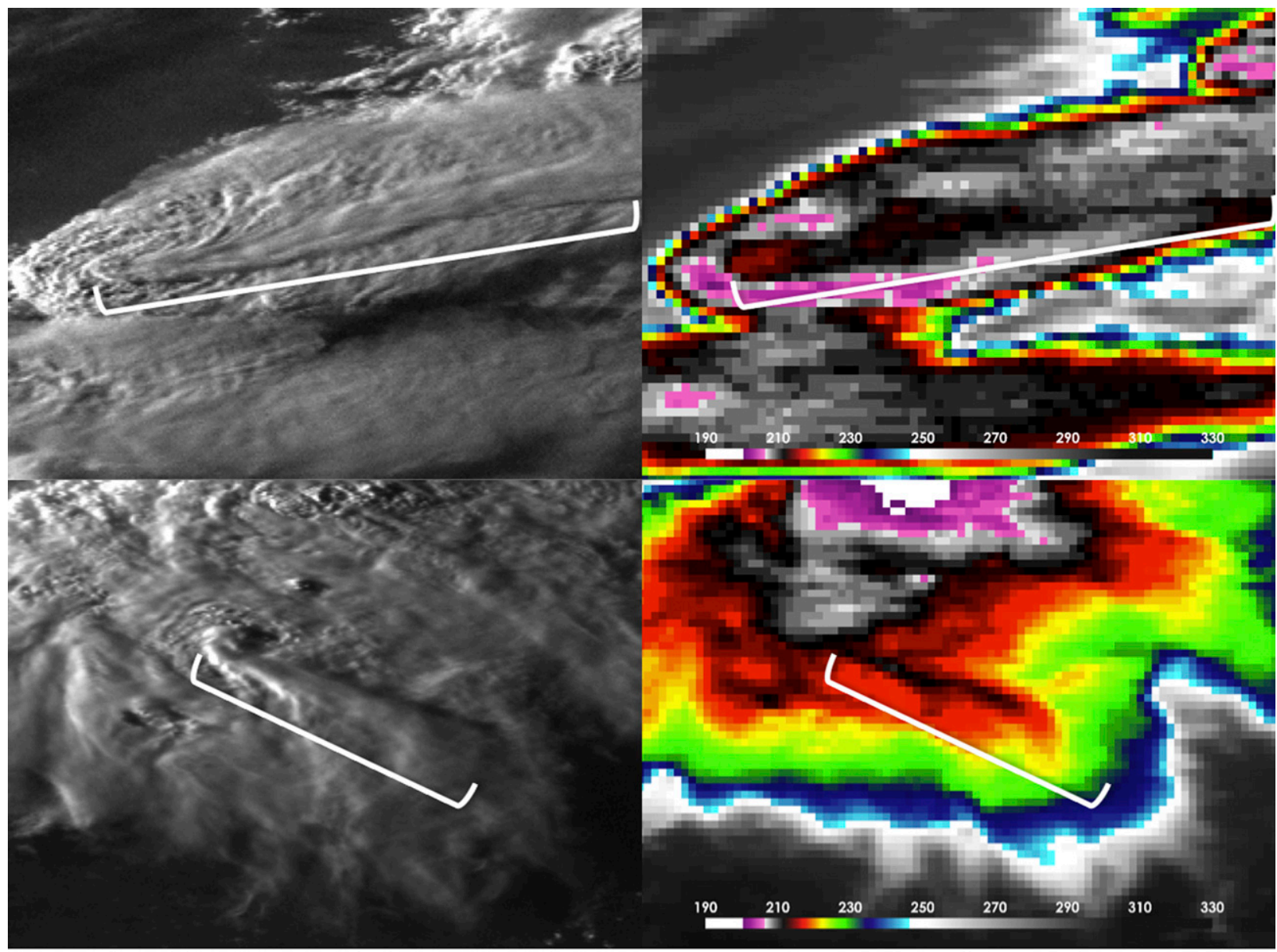

FIG. 2. Two examples of prominent above-anvil cirrus plumes in GOES (left) visible and (right) IR imagery. GOES-12 imagery at 0015 UTC 6 May 2002 (top) and GOES-14 imagery at 0031 UTC 21 Aug 2012 (bottom). The white brackets indicate the spatial extent of the plumes.

three of the five storms because of the 30-min gap in the SRSOR imagery from 2245 to 2315 UTC. GOES-13 provided 7.5-min rapid scan observations on 16 August and these data were used to fill in the GOES-14 gap of 30 min from 1945 to 2015 UTC.

The number of lightning flash detections from NLDN, ENTLN, and NALMA (2-3 September only) within $15 \mathrm{~km}$ of the storm center was also computed at 1-min intervals. The $15-\mathrm{km}$ radius was chosen because it encompassed all the lightning activity produced by the storms and did not include lightning from nearby storms. As 1-min lightning flash rates can appear somewhat noisy relative to the other datasets, the lightning time series are smoothed using a three-point weighted average with the middle point being assigned double the weight of the other two. The maximum echo-top heights at the three reflectivity levels from the nearest WSR-88D and MESH within the storm were also recorded.

\section{b. Above-anvil cirrus plume identification}

In addition to the analysis described above, aboveanvil cirrus plumes were identified in visible imagery throughout the duration of the 2012 SRSOR period. No fewer than 2000 individual convective anvils (a conservative estimate) were examined in detail but only a small subset of these anvils had a plume. The visible image contrast was interactively adjusted to account for solar illumination variability so that the plumes could be better identified. The time of emergence of the plumes and their relation to the time of severe weather reports was determined. Examples of well-defined plumes are shown in Fig. 2. One can determine that the plume is indeed above anvil because of 1) its apparent attachment to an OT region, 2) shadowing induced by the height differential between the plume and underlying anvil, and 3) the differing texture of the plume relative to the anvil, possibly caused by differences in cloud 
microphysics. Only the plume in Fig. 2 (top) is anomalously warm, contributing to the enhanced V signature. Despite the variability in plume BT, both storms produced severe weather after the plumes appeared. Visible imagery is most effective for plume identification here because its spatial resolution is a factor of 16 finer than the IR channel resolution, but plumes would also be apparent in 1.6- and 3.7- $\mu \mathrm{m}$ channel imagery provided by the GOES-R ABI (Levizzani and Setvák 1996).

The time of emergence of the plumes and their relation to the time of severe weather reports was determined. If a plume emerged ahead of the severe weather report, we state that the plume offered severe weather forecast lead time. The lead time provided by SRSOR imagery is compared with the lead time that would have been provided if GOES were scanning in operational 15-30-min mode. The scan schedule of GOES-13 is the basis of this analysis (http://www.ospo. noaa.gov/Operations/GOES/east/imager-routine.html). The time stamp of the GOES images provided at this link indicates the beginning of the scan at the northern edge of the domain. The northern edge changes depending on the type of GOES scan (i.e., "CONUS" versus "Full Disk") so there is a considerable delay (3-9 min) between the time a plume-producing storm was actually observed by GOES and the nominal image time stamp. We used McIDAS-X to determine the exact time that a plume would have been observed by operational GOES depending on the scan type that would have occurred at the image time.

\section{c. Computation of overshooting top height}

OT height estimates are included in this study because no previous studies have examined height variability at 1-min intervals and its relation with other observations. OTs create shadows on a small portion of the anvil because they are higher than the anvil and obstruct sunlight. The length of the shadow is modulated by the solar zenith angle and height differential between the OT and anvil. A more prominent OT will produce a longer shadow than one with a lesser height differential and the shadow length will increase for an OT with constant height as the sun moves closer to the horizon.

The computation of OT-anvil height differential requires identification of the coordinates of the highest pixel of the OT and the end of the shadow induced by the OT. A visible channel pixel next to (along the path of solar illumination) the brightest pixel in the OT region is considered the highest pixel; the brightest pixel will typically be on the side of the OT at high solar zenith angle, not the very top. To derive an accurate shadow measurement, the anvil must be spatially uniform without other vertical protrusions such as another OT that obscures the shadow end.

The two 2-3 September storms provided an opportunity to derive OT heights for a portion of their lifetime. The OT peak, shadow end, and GOES image were input into the OT-anvil height differential retrieval method described by Kanak et al. (2012). OT occurrence was determined through subjective human analysis of visible channel imagery, which is independent of whether or not the OT was detected by the automated IR-based algorithm described in section $2 \mathrm{~b}$. The anvil was assumed to reside at the $16.2-\mathrm{km}$ equilibrium level from the sounding at 0000 UTC 3 September in Birmingham, Alabama. The OT-anvil height differential was added to the equilibrium level to compute a final OT height. Though the height retrieval method is mathematically robust, there are no available methods for validating the derived OT heights so the relative changes across an image sequence is the focus, not the specific height value at any given time.

\section{d. Caveats}

When interpreting the following results, it is critically important to understand that the GOES BTs within the updraft regions of deep convective storms will not match those that would be observed by the ABI. ABI will offer 4 times the spatial sampling of GOES-14 and improved signal-to-noise ratio, which will have a significant impact on the BT observations within small-scale features such as OTs. Hillger et al. (2013) reported a 7-K difference between MODIS and GOES-13 for one OT and Bedka et al. (2010) reported a 12-K mean difference for many OT events observed by MODIS, AVHRR, and GOES-12. The GOES-14 IR pixel size is $\sim 6 \mathrm{~km}$ over the CONUS; thus, one should assume that the BT oscillations would be much more pronounced and indicative of changes in storm intensity/severity if they were observed by the ABI.

Severe weather report accuracy has a significant impact on our results. Severe weather is often underreported, especially in sparsely populated areas (Dobur 2005; Cecil 2009). Severe weather report time errors of 5-10 min are quite possible and significant when one attempts to draw conclusions about trends from 1-min datasets. The multidataset time series will illustrate that rapid fluctuations often occur near severe weather reports. Yet similar, if not more pronounced, trends occur at other periods in the time series, but no severe weather was reported near these times and it cannot be determined if severe weather actually occurred. Unreported severe weather, errant reports (i.e., no severe weather actually occurred), and report timing error will also affect the above-anvil cirrus plume-severe weather relationships. While the SPC performs quality control and 
encourages severe weather reporting by the general public, nothing can realistically be done to address a lack of a report or errant reports; therefore, one must be careful in drawing definitive conclusions from the following analyses. Specifically, the statistical agreement between plume and severe weather events described in section $4 \mathrm{~d}$ is considered to be a low estimate given that many of the plume events occurred over rural areas in the CONUS and some severe weather may not have been reported.

Last, the ENTLN dataset is relatively new to the community and an assessment of ENTLN flash detections had not been documented until recently when Thompson et al. (2014) compared ENTLN to the Tropical Rainfall Measuring Mission Lightning Imaging Sensor (Christian et al. 1992). Their results are only valid for areas south of $38^{\circ} \mathrm{N}$ and east of the Rocky Mountains. For example, over northern Alabama (section 4a) the estimated ENLTN flash detection efficiency varied between $70 \%$ and $80 \%$. In southern Missouri and southern Illinois (section 4b), Thompson et al. found ENTLN flash detection efficiencies of $60 \%-80 \%$ and $80 \%-90 \%$, respectively. ENTLN data outside of this area (e.g., the Wisconsin case in section $4 \mathrm{c}$ ) are assumed to have similar detection efficiencies $(60 \%-90 \%)$ but ENTLN characteristics are unconfirmed in these regions.

\section{Results}

\section{a. Severe wind and nonsevere storm events: 2}

\section{September 2012}

Thunderstorms developed near 2100 UTC in northwestern Alabama along a region of surface wind convergence and a local $700-\mathrm{hPa}$ wind speed maximum along the southern flank of the remnant circulation of the former Hurricane Isaac. Two storms were studied for this event. Storm 1 produced winds that damaged power lines near Fairview, Alabama, at 0003 UTC. Storm 2 produced a long-lived OT signature that was apparent in visible imagery but was not associated with any severe weather reports. Figures 3 and 4 provide a time series of satellite, lightning, and radar datasets for these storms.

Monitoring of storm 1 began at 2320 UTC when a distinct BT minimum and the first signs of an OT were present (not shown). The minimum BT remained relatively consistent until 2333 UTC when the cloud top began to cool and increase in height and the OT signature became more prominent, signaling updraft intensification. The colder cloud top allowed the GOES OT detection algorithm to begin to identify the OT signature as it became $>6 \mathrm{~K}$ colder and reached a height of $1.8 \mathrm{~km}$ above the surrounding anvil (Fig. $3 \mathrm{~b}$ ). Both the total and CG lightning flash rates began to increase at this time as did the $40-\mathrm{dBZ}$ echo top. MESH was relatively constant throughout the storm lifetime, as this was a damaging wind event and not a hailstorm for which the MESH product is most applicable.

The BT and 18.5- and 30-dBZ echo-top fields indicated the coldest cloud top during the storm lifetime was from 2346 to 2348 UTC (Fig. 3c). The OT shadowderived height was rising prior to the 4-min image gap between 2341 and 2345 UTC and may have peaked during the gap, but no height peak was coincident with the BT minimum. After 2349 UTC, the cloud top warmed and the OT shadow-derived height decreased but OT detections continued as an OT was still present. Despite the apparent updraft weakening near cloud top suggested by the GOES data and 18.5-30-dBZ echo tops, the lightning flash rates continued to increase, most notably in the NALMA dataset. The 40-dBZ echo top also continued to increase; thus, it is likely that the convective updraft at midlevels of the storm was still sufficiently vigorous to promote continued riming growth of precipitation ice, charging, and lightning production. Solar illumination was no longer sufficient to get an accurate OT shadow-derived height after 2356 UTC.

At 2400 UTC (i.e., 0000 UTC 3 September), the cloud top continued to warm and the echo top decreased rapidly, signaling the collapse of the storm core that initiated a severe downdraft that impacted Fairview. An OT signature was sporadically detected in the following minutes but the accuracy of these detections could not be verified without visible imagery. The storm rapidly decayed after 0010 UTC.

The multidataset time series for storm 2 (Fig. 5) illustrates that the BT was quite similar to storm 1 at the beginning of their respective monitoring periods and the two storms remained within the same 195-205-K BT range throughout their lifetimes. GOES imagery shows a similar appearance between the two storms with both exhibiting an OT signature and a small BT minimum. An OT was present continuously from 2315 to 2356 UTC but its shadow intersected the OT from storm 1 , so OT heights could only be derived during 2315-2346 UTC. Similar to most of the storm 1 time series, the OT shadow-derived heights followed the BT well from 2318 to 2326 UTC. The downward trend in height agreed better with the 18.5- and 30-dBZ echo tops than the BT. An OT was detected near the time in Figs. 3a-d when the BT minimum became more prominent but many OTs were undetected at other times because the OT BT signature was not very distinct.

The 30- and 40-dBZ echo tops and lightning flash rates gradually increased from 2330 to 0000 UTC. The $18.5-\mathrm{dBZ}$ echo top exceeded $16 \mathrm{~km}, \sim 1 \mathrm{~km}$ higher than the peak height of storm 1 , and the $30-$ and $40-\mathrm{dBZ}$ echo 

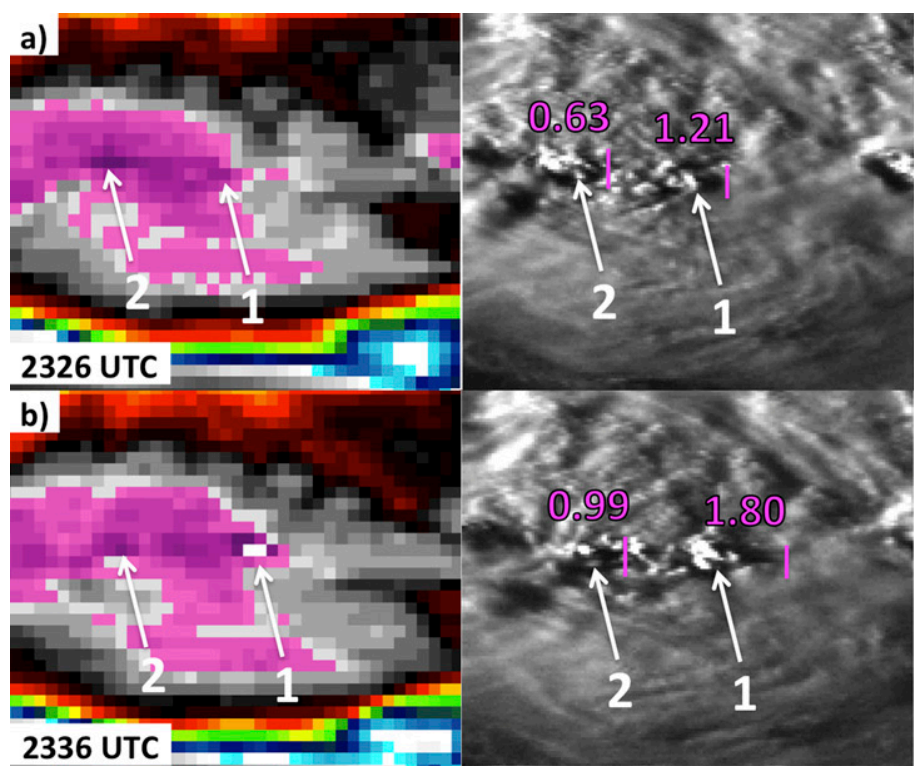

c)
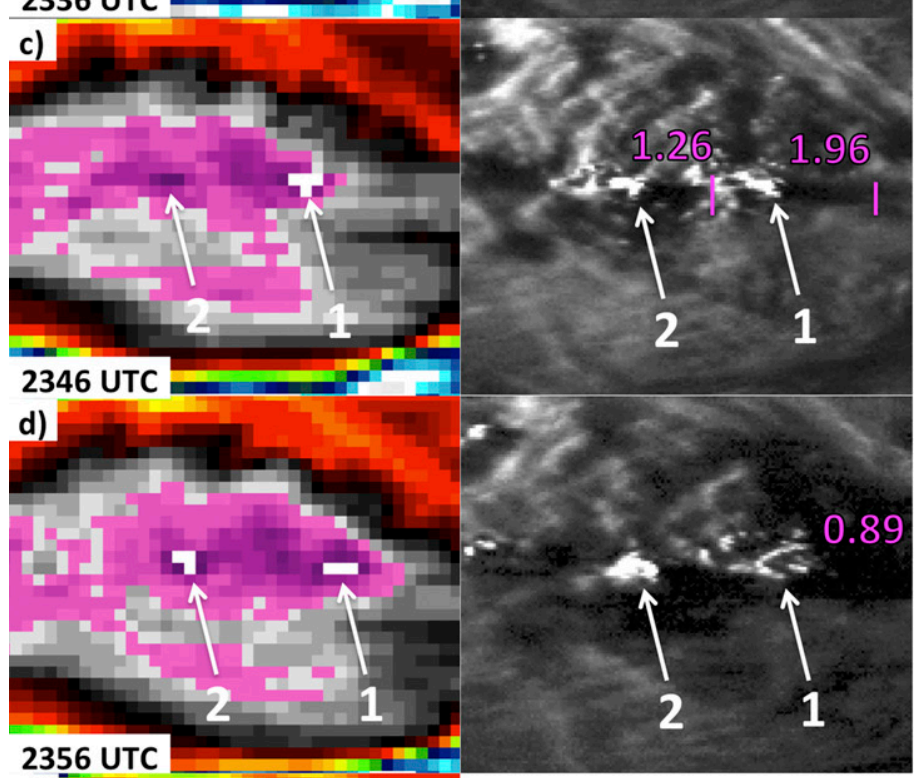

e)

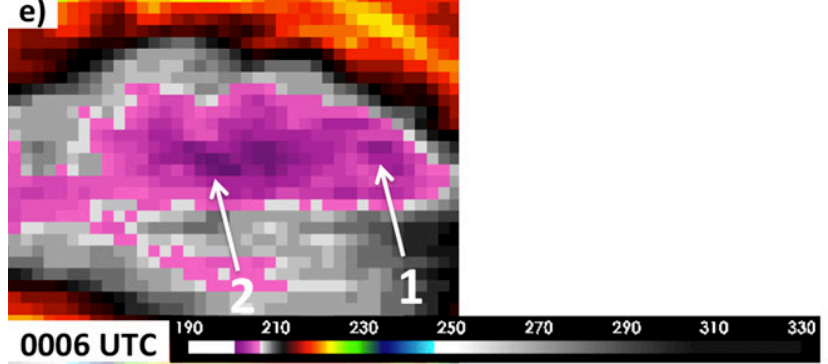

FIG. 3. GOES-14 (left) $10.7-\mu \mathrm{m} \mathrm{BT} \mathrm{(K)} \mathrm{and} \mathrm{(right)} \mathrm{visible} \mathrm{imagery} \mathrm{at}$ 10-min intervals on 2-3 Sep 2012 over northern Alabama. The two storms of interest are numbered with white arrows. The color table corresponding to the BT color enhancement is provided along the bottom. Magenta lines (right) in (a)-(c) show the end of the OT-induced shadow and the magenta numbers above the shadows show the magnitude of OT penetration above the anvil $(\mathrm{km})$ computed from the shadow length and solar illumination geometry following Kanak et al. (2012). No visible image was provided for (e) because of insufficient solar illumination. 

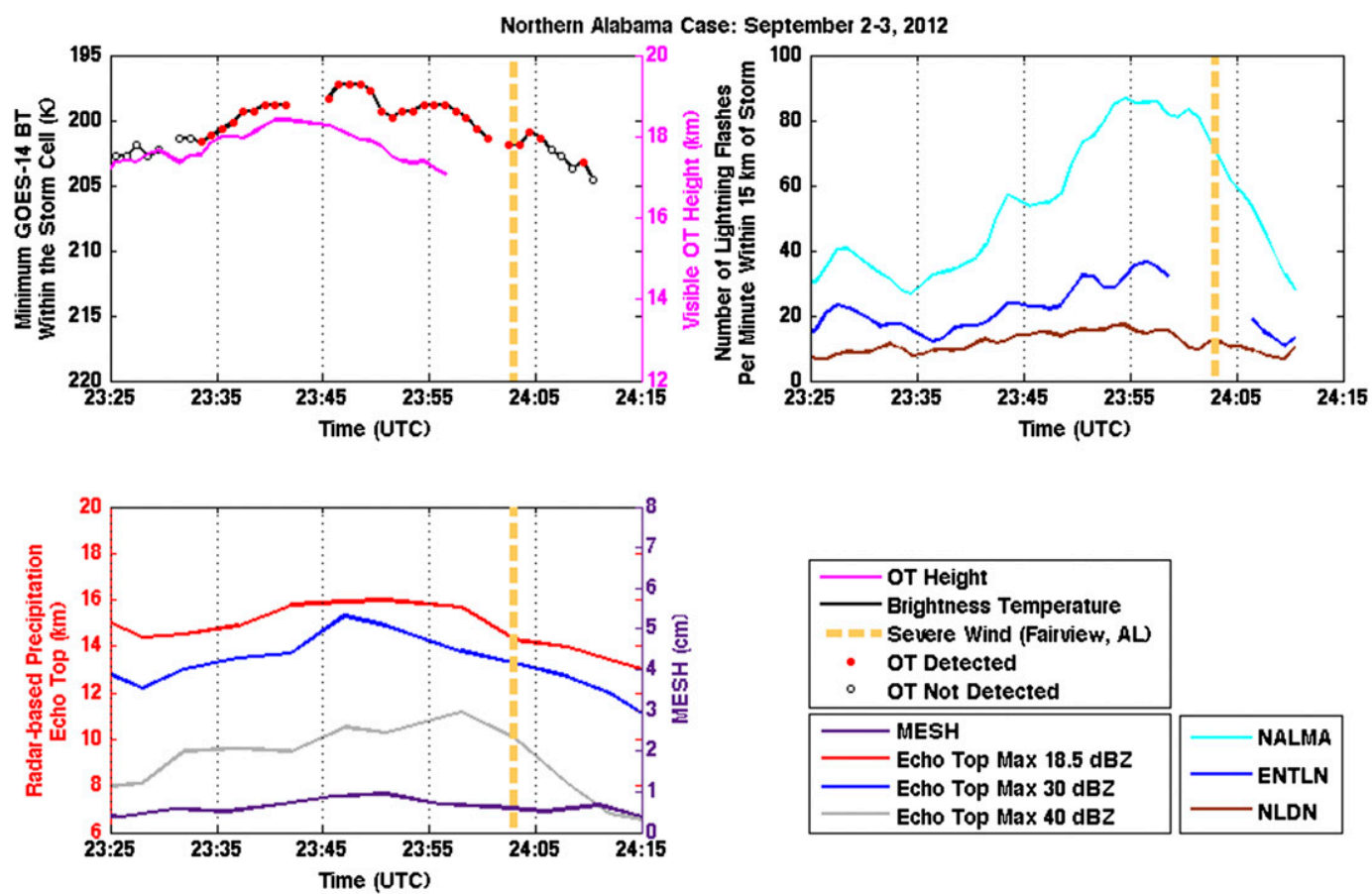

FIG. 4. (top left) GOES-14 min 10.7- $\mu \mathrm{m}$ BT and objective OT detection time series for storm 1 on 2-3 Sep. (top right) NALMA, ENTLN, and NLDN lightning flash detection time series. (bottom) WSR-88D multireflectivity echo-top time series from the Huntsville radar and MESH time series. The time of a severe wind report is identified with a vertical dashed line.

tops also reached peak values near 0000 UTC shortly after cloud-top cooling and frequent GOES OT detection. The $30-\mathrm{dB} Z$ tops were a bit higher in storm 2 than in storm 1 , but $40-\mathrm{dB} Z$ echo tops were comparable at their respective peaks. After 0000 UTC, the echo-top height showed a downward trend with the decrease accelerating after 0010 UTC. The NALMA lightning flash rate also increased, though not at the same rate as storm 1 prior to the damaging wind report. Storm 2 continued to decay after the end of the monitoring period and its BT signature became indistinguishable.

The lightning flash rate time series from NALMA, ENTLN, and NLDN for the two storms show interesting relationships. NALMA consistently observed the greatest flash rates except for the beginning of the storm 2 time series. Storm 2 was $\sim 85 \mathrm{~km}$ away from the center of NALMA at 2315 UTC, but it progressed eastward closer to the center throughout the analysis period. This distance could have reduced the NALMA detection capability to some extent. As expected, the NLDN CG flash rates were significantly lower than those from the total lightning detection networks, especially in advance of the severe wind from storm 1 . Vigorous deep convection favors IC discharges from the developing to mature stages (Williams et al. 1989). In general, IC tends to outnumber CG discharges by a factor of $\sim 3: 1$ (Boccippio et al. 2001) but the IC:CG ratio can be much larger during the growth phase of vigorous and severe convection (MacGorman et al. 1989).

A close examination of the NALMA and ENTLN time series reveals that the trends in flash rate observed by the two networks were quite similar and many of the subtle high-frequency variations in flash rate were captured, especially within storm 1 . The relatively close qualitative agreement between the robust, well-documented NALMA and the much newer ENTLN, along with the fact that ENTLN sensors are well distributed across the country, indicate that ENTLN could be used for the other case studies.

\section{b. Large-hail events: 16 August 2012}

Thunderstorms developed around 1715 UTC ahead of and along a strong cold front across Illinois, southern Missouri, and Arkansas. A widespread outbreak of convective storms eventually occurred with 77 severe weather reports from 1755 to 2359 UTC across the region. Two storms were monitored at 1-min intervals for this event; the first storm produced 2.5-in. hail in Gorham, Illinois, at 2030 UTC and the second produced 2.75-in. hail at 2230 UTC in Pierce City, Missouri. Figures 6-9 provide a time series of satellite, lightning, and radar datasets for these storms. 

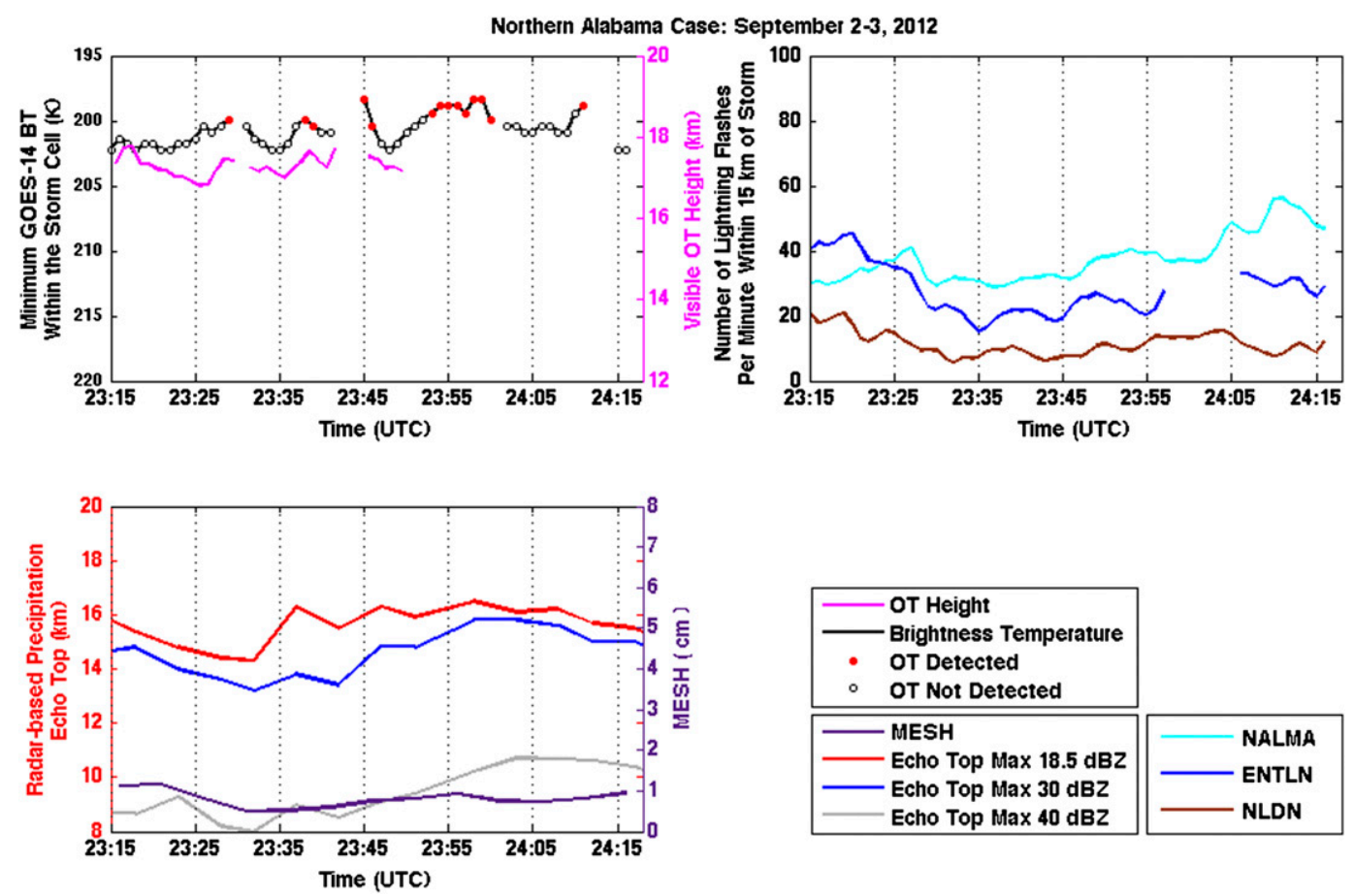

FIG. 5. As in Fig. 4, but for storm 2 on 2-3 Sep.

Monitoring of the Gorham hailstorm began at 1935 UTC when an OT was evident in GOES imagery (not shown) and detected (not shown). The cloud top cooled steadily through 1945 UTC as echo-top heights at all reflectivity levels and MESH increased and an OT was frequently detected (see Fig. 6a for GOES imagery). In contrast with other cases, lightning activity remained relatively constant despite the storm intensification period, as depicted by satellite and radar. High-frequency oscillations on 0-10-min time scales are evident but the general trend over 20-30 min shows increasing flash rates more in line with a general upward trend in echo-top heights ( $40 \mathrm{dBZ}$ especially).

GOES-14 performed a full-disk scan from 1945 to 2015 UTC, so the 7.5-min rapid scan BT from GOES-13 and OT detection data were used during this period. The cloud top cooled rapidly from the 1945 UTC GOES-14 image to the 1958 UTC GOES-13 image, reaching the lowest BT during the storm lifetime. The lightning flash rates, echo tops, and MESH also increased during this period. The storm had a second period of rapid cloudtop cooling from 2017 to 2022 UTC, but echo top and lightning flash rate generally decreased. An above-anvil cirrus plume became evident at 2026 UTC, shortly after the cloud-top cooling ceased. The cloud top then warmed rapidly and $30-$ and $40-\mathrm{dB} Z$ echo tops decreased as severe hail was observed in Gorham. MESH peaked near $7 \mathrm{~cm}$ shortly after the hail report. OT detections ceased at 2038 UTC and the storm remained relatively steady state for the remainder of the period.

Monitoring of the Pierce City hailstorm began at 2130 UTC shortly after storm initiation. Only NLDN CG lightning flashes were detected in the first $10 \mathrm{~min}$ of the period as the cloud top cooled by $\sim 15 \mathrm{~K}$ and a cirrus anvil developed (Figs. 9a,b). NLDN flash rates exceeded ENTLN from 2130 to 2150 UTC, which is a bit peculiar in that NLDN did not exceed those from the total lightning networks for any of the other storms. On the other hand, flash rates from both networks were generally very low $\left(<5\right.$ flashes $\left.\mathrm{min}^{-1}\right)$ during this period. The 18.5 -dBZ echo top increased by $\sim 3 \mathrm{~km}$ over a 5 -min period starting at 2150 UTC and remained above the $16-\mathrm{km}$ level until the end of the monitoring period. This rapid increase in echo top coincided with a 5-K BT decrease. One might have expected a significant increase in echo top after 2130 UTC when the cloud top cooled at a $10 \mathrm{~K}(5 \mathrm{~min})^{-1}$ rate, but in fact the increase was only $\sim 0.5 \mathrm{~km}$. The MESH time series mirrored the echo top.

After 2200 UTC, the BT minimum became distinct relative to the surrounding anvil (Figs. $8 \mathrm{c}-\mathrm{e}$ ) and OTs were detected for the next $30 \mathrm{~min}$ as total lightning flashes became more numerous. An above-anvil cirrus plume appeared at 2217 UTC during a period of cloudtop cooling and shortly after a rapid MESH increase, indicative of updraft intensification. The storm echo top 

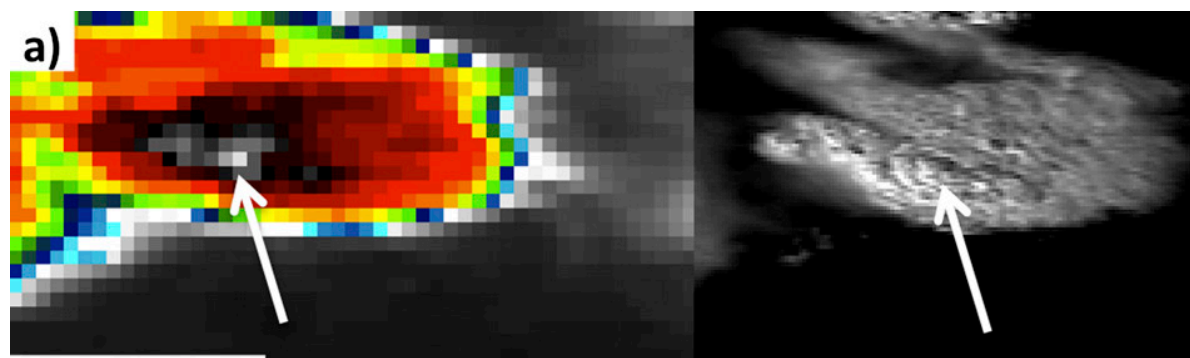

\section{UTC}
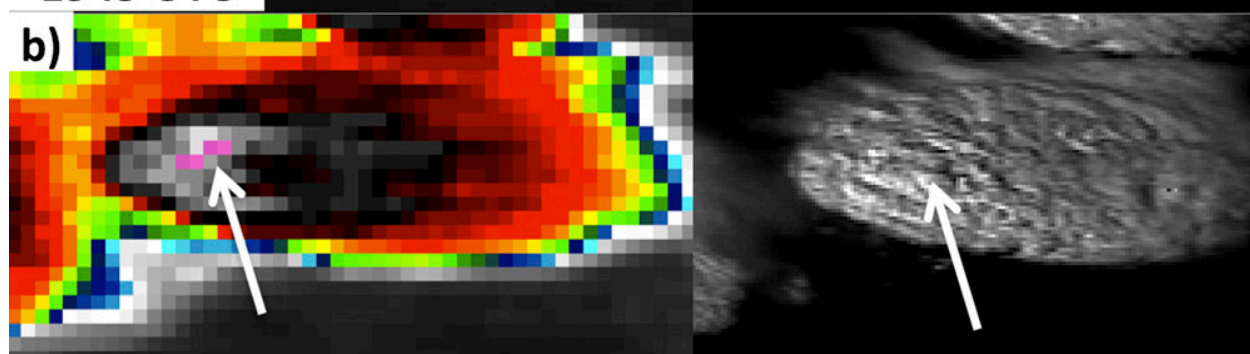

\section{UTC}
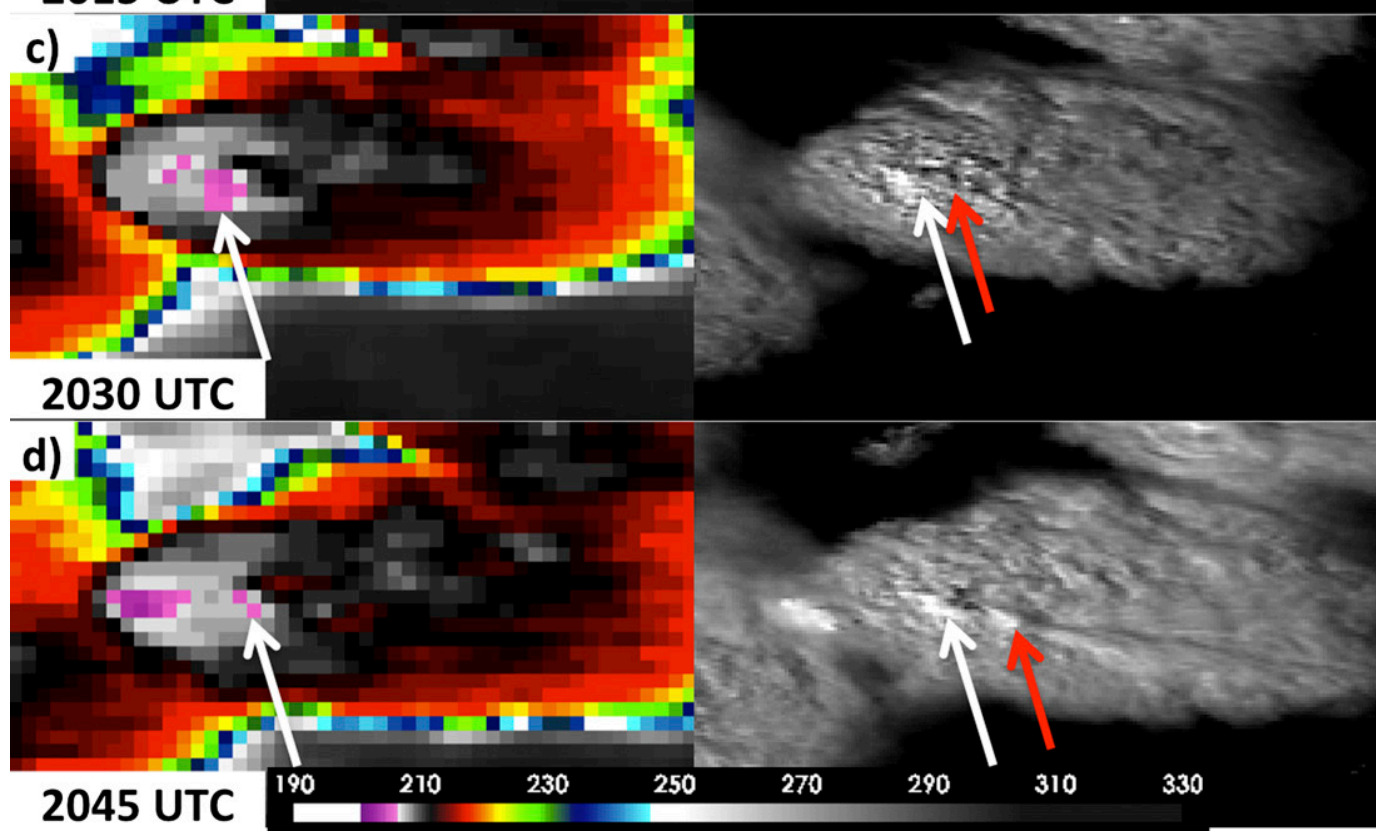

FIG. 6. GOES-14 (left) 10.7- $\mu \mathrm{m} \mathrm{BT} \mathrm{(K)} \mathrm{and} \mathrm{(right)} \mathrm{visible} \mathrm{imagery} \mathrm{at} \mathrm{15-30-min} \mathrm{intervals} \mathrm{from} 1945$ to 2045 UTC for the Gorham hail event on 16 Aug 2012. The hail-producing storm is identified with a white arrow and an aboveanvil cirrus plume is identified with a red arrow. The color table corresponding to the BT color enhancement is provided along the bottom.

reached its peak and BT was coldest shortly after 2220 UTC. The cloud top then warmed at an $8 \mathrm{~K}$ $(5 \mathrm{~min})^{-1}$ rate and the echo top collapsed by $2 \mathrm{~km}$ as severe hail was observed in Pierce City. The peak MESH value of $4 \mathrm{~cm}$ was a significant underestimate of the reported hail size. After this time, the storm core was indistinguishable from the surrounding anvil and monitoring ended (Fig. 8f). c. Southwestern Wisconsin hail and tornado events: 4 September 2012

Thunderstorms developed at $\sim 2030$ UTC near a weak surface low and prefrontal trough axis in the upper Mississippi River valley region. The 4-5 September event featured 36 severe weather reports from 2100 to 0045 UTC. The storm of interest had developed at $\sim 2215$ UTC 

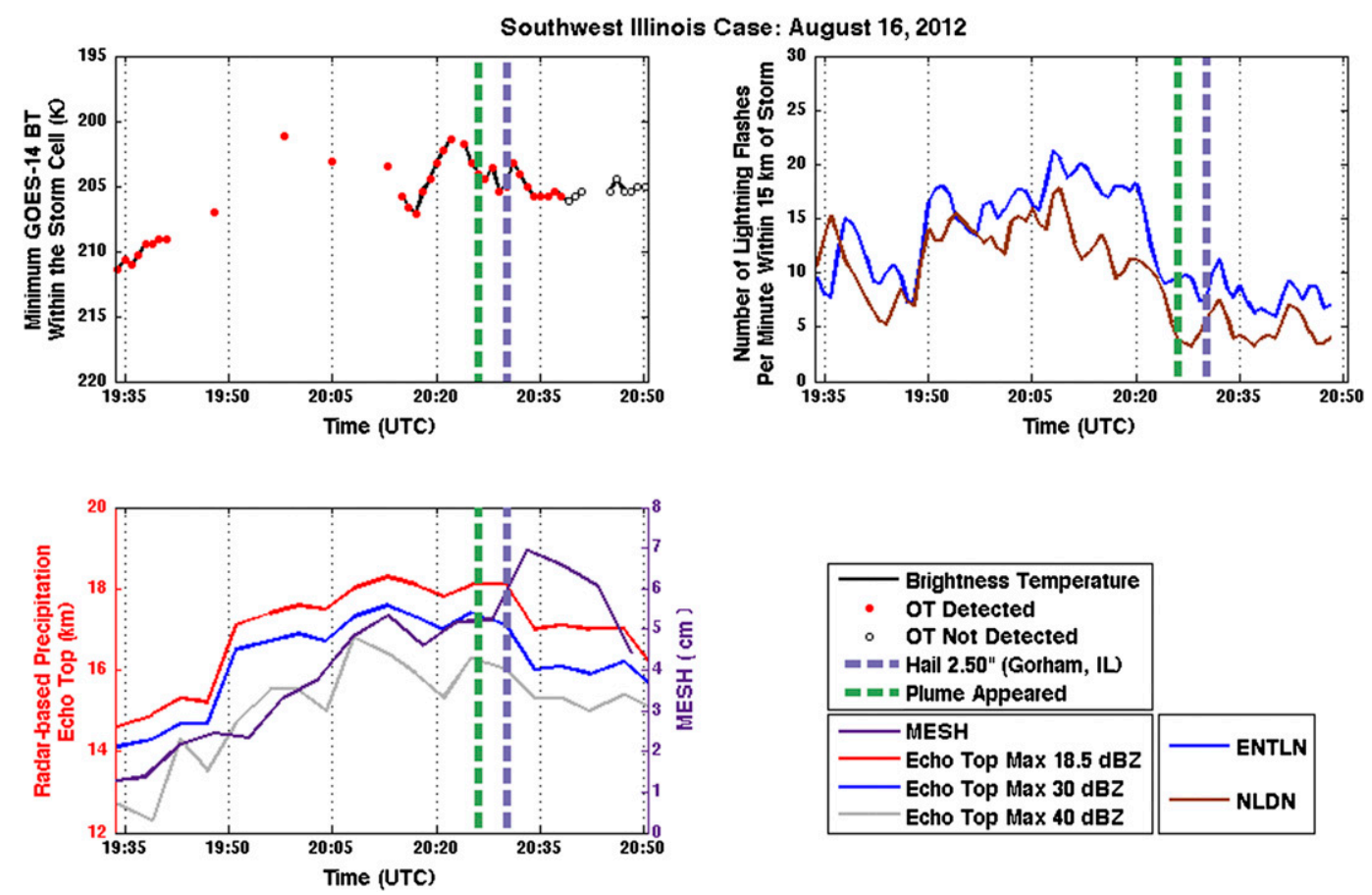

FIG. 7. As in Fig. 4, but for the storm that produced severe hail in Gorham on 16 Aug. NALMA data are not available over this region.

in northeastern Iowa and moved southeast until it was absorbed by a developing mesoscale convective system at $\sim 0100$ UTC 5 September. The storm produced 1.75-in. hail in Marquette, Iowa; 1.25-in. hail in Prairie du Chien, Wisconsin; and 1.00-in. hail in Brodtville, Wisconsin, from 2331 to 2356 UTC, as well as an EF2 tornado near Bloomington and Patch Grove, Wisconsin, at 0038 UTC. Figures 10 and 11 provide a time series of satellite, lightning, and radar datasets for this storm.

Following the 2245 UTC full-disk scan, monitoring of the storm began at 2315 UTC and an OT, distinct BT minimum, and MESH maximum were already present at this time (Fig. 10a). The NLDN flash rates are multiplied by 10 for this case for plotting purposes, indicating that the IC lightning activity far exceeded the CG activity even though the two lightning datasets show very similar time trends throughout the monitoring period.

An above-anvil cirrus plume had already been produced sometime in the 2245-2315 UTC time frame but a second plume emerged at 2323 UTC in association with a period of cloud-top cooling $\left[5 \mathrm{~K}(5 \mathrm{~min})^{-1}\right]$ and redevelopment of an OT. A plume was also present in a storm to the northwest that produced severe wind in Goose Island, Wisconsin, at 2313 UTC. The BT warmed slightly $(2 \mathrm{~K}$ ) from 2328 to 2331 UTC (see Fig. 11b for a GOES image during this time) corresponding to the time of the Marquette hail report.
The storm then intensified again from 2332 to 2341 UTC with cloud-top cooling, a rapid echo-top height increase to its highest values during the storm lifetime $(17.8 \mathrm{~km}$ at $18.5 \mathrm{dBZ})$, a sharp increase in ENTLN flash rate, and frequent OT detections. Plume production that had begun at 2323 ended at 2341 UTC. A sharp BT increase $(4.5 \mathrm{~K})$ and sharp decrease in ENTLN flash rate preceded the Prairie du Chien hail report at 2346 UTC. An OT was not detected at this time due to the cloud-top warming but it was still evident in visible imagery (Fig. 10c).

The BT oscillated over the following $10 \mathrm{~min}$ with OTs being detected at all times except for a 2-min period near 2350 UTC. New plume production began again at 2347 UTC during a period of cloud-top cooling. The area of cold BT expanded (Fig. 10d) and the BT reached the coldest value during the storm lifetime at 2357 UTC along with a $\sim 4-\mathrm{cm}$ MESH. A relative maximum in total lightning occurred 2 min earlier, sandwiching the Brodtville hail report at 2356 UTC.

After 0000 UTC, the BT oscillated periodically with $\sim 12-13$ min between BT minima and variations in the BT time series generally agreeing with echo-top heights and MESH. OTs were detected near BT minima as the cold region became prominent relative to the surrounding anvil cloud (Figs. 10e,f). The ENTLN trend followed the BT time series to some degree with relative 

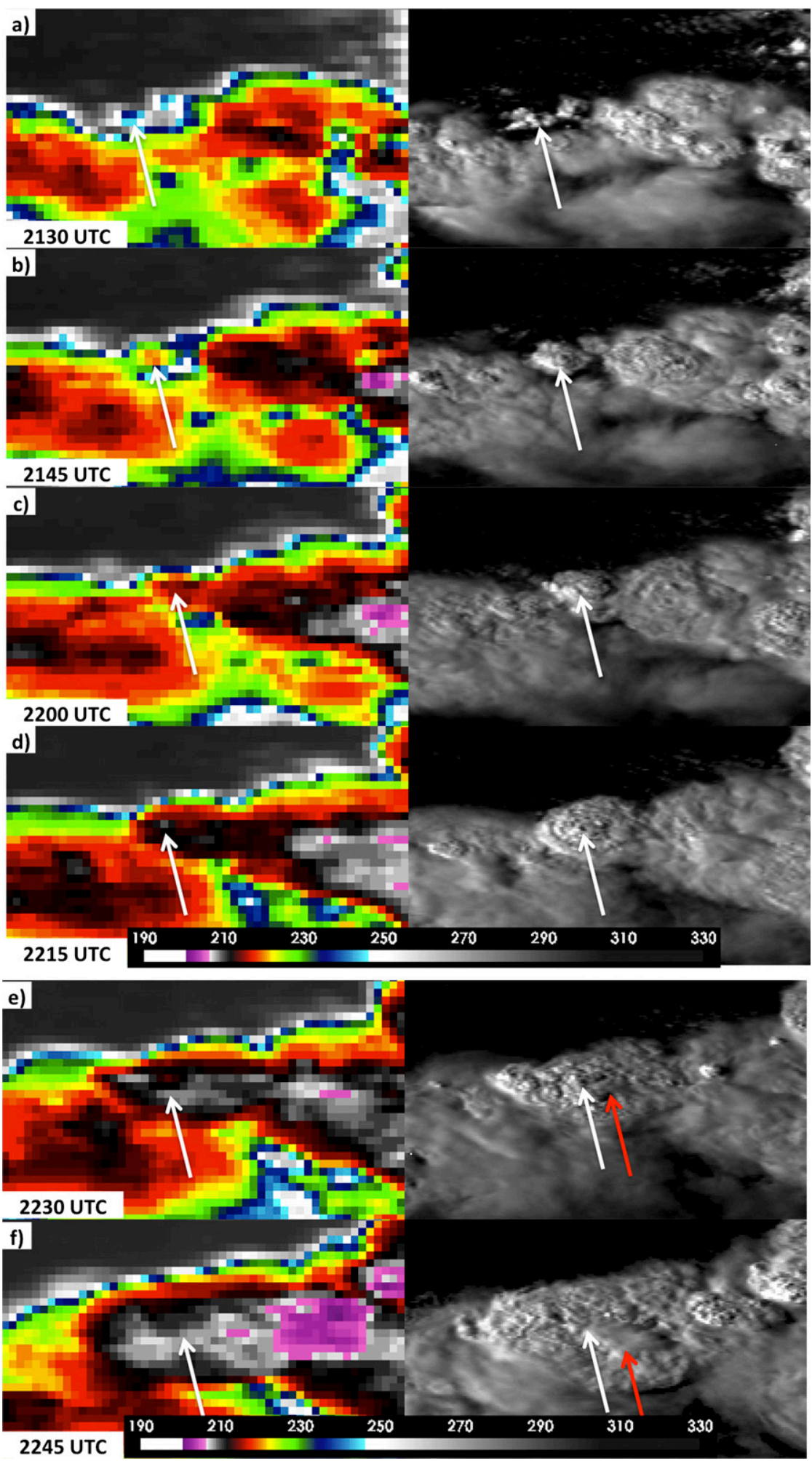

FIG. 8. GOES-14 (left) 10.7- $\mu \mathrm{m} \mathrm{BT} \mathrm{(K)} \mathrm{and} \mathrm{(right)} \mathrm{visible} \mathrm{imagery} \mathrm{at} \mathrm{15-min} \mathrm{intervals} \mathrm{from}$ 2130 to 2245 UTC for the Pierce City hail event on 16 Aug 2012. The hail-producing storm is identified with a white arrow. The color table corresponding to the BT color enhancement is provided along the bottom. 

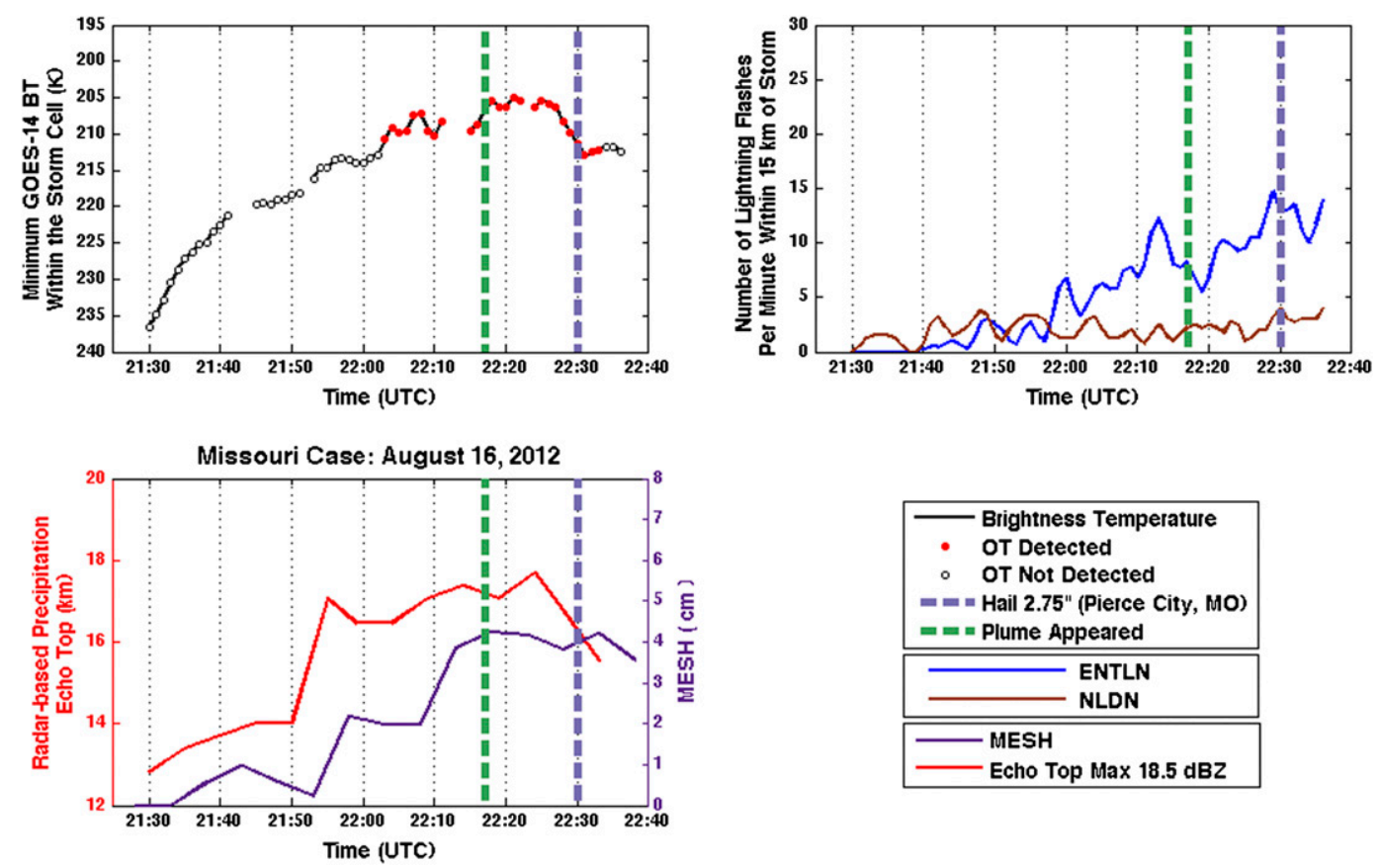

FIG. 9. As in Fig. 4, but for the storm that produced severe hail in Pierce City on 16 Aug. NALMA and the 30- and 40-dBZ echo-top data are not available over this region.

maxima in flash rate occurring very close in time to the coldest BTs. ENTLN and NLDN flash rates increased sharply from 0034 to 0038 UTC as the cloud top cooled once again. Lightning jumps occurred just prior to or during severe weather occurrence, including the EF2 tornadoes. A relative BT minimum, peak lightning flash rate, and subtle dip in echo tops occurred at the time of tornado touchdown at 0038 UTC. The cell was absorbed by a developing mesoscale convective system after 0050 UTC so the storm monitoring ended at this time (Fig. 10h).

\section{d. Identification of above-anvil cirrus plumes}

Visible imagery for every convective storm over the CONUS during the 2012 SRSOR period was analyzed in detail to identify the presence and timing of the first identification of above-anvil cirrus plumes. Plumes were produced by three of the four severe storms described above suggesting that they could be an early indicator of a severe storm, increasing forecaster awareness of a hazardous storm and yielding an increase in warning lead time.

Our analysis indicates only a small subset of OTproducing storms also produced a plume, but when a plume is present, the storm is more likely to be severe than nonsevere. For the 16 August event discussed in this paper, 25 plumes were produced and 13 of the plumeproducing storms were severe. For the 2-3 September event, two distinct plumes were produced and both of them were from a severe storm. Faint plumelike features were also present atop several severe storms in northwestern Alabama but these plumes were not very long lived nor were we able to pinpoint an exact time of initial plume emergence so they were not counted in this analysis. For the 4-5 September event, eight plumes were produced and seven of the plume-producing storms were severe. When all 30 GOES-14 SRSOR days with imagery over the CONUS are combined, 58 storms produced plumes and $33(57 \%)$ of the plumeproducing storms were associated with a severe weather report. Plumes appeared in advance of a severe weather report for 28 of the 33 (85\%) events. For the five events with no lead time, the plumes emerged a maximum of $10 \mathrm{~min}$ after the severe weather report. For the other 28 events, the plumes appeared an average of $18 \mathrm{~min}$ in advance of severe weather with a standard deviation of $14 \mathrm{~min}$. The large standard deviation was caused by seven of the plumes providing greater than $30 \mathrm{~min}$ lead time.

The lead time that would be offered by GOES if it were operating in 15-30-min operational scanning mode was computed to compare with the SRSORbased results. A plume would have been observed prior to the severe weather report for only $48 \%$ of the plume events if GOES were in normal operations. For events with lead time from both SRSOR and operational scanning, SRSOR provided a 27-min mean lead time and the operational imagery would have provided an 18-min lead time. 

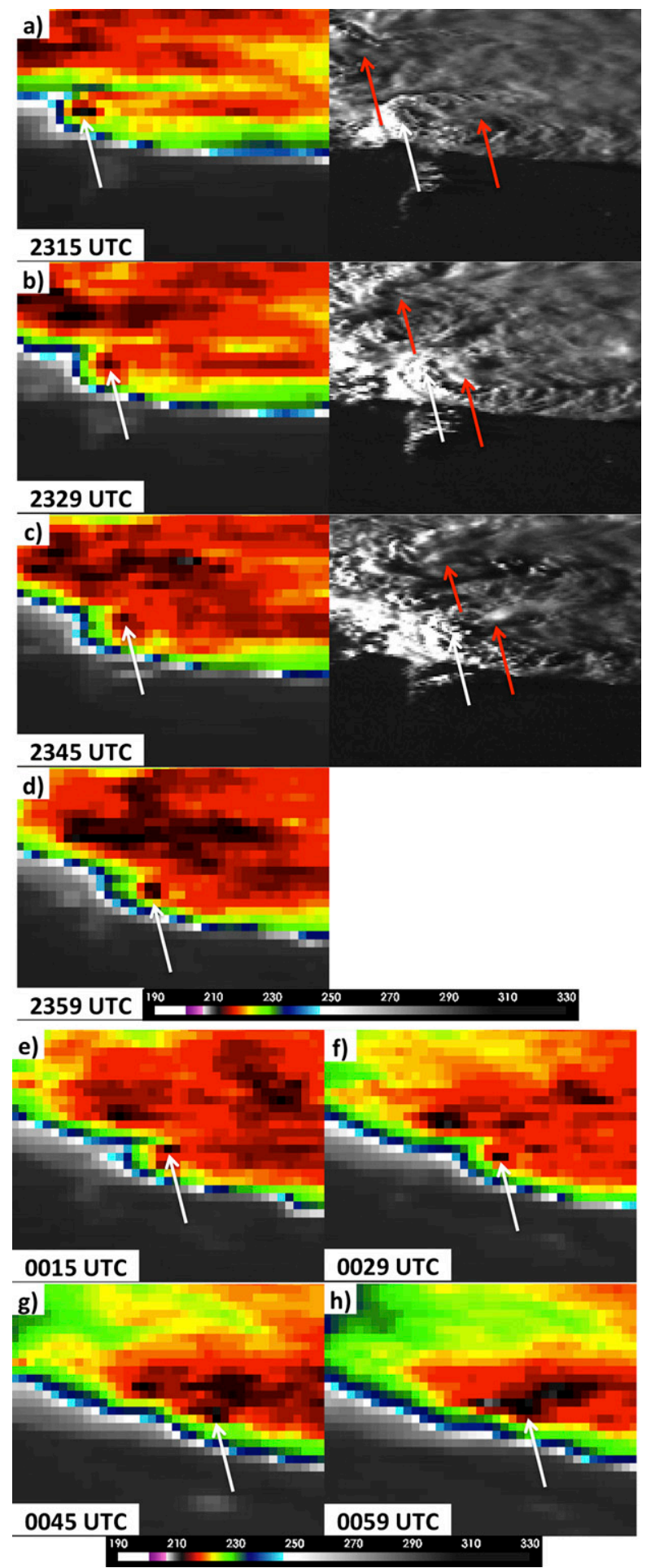

FIG. 10. GOES-14 (left) 10.7- $\mu \mathrm{m} \mathrm{BT} \mathrm{(K)} \mathrm{and} \mathrm{(right)} \mathrm{visible} \mathrm{im-}$ agery at 14-16-min intervals from 2315 to 0059 UTC for the storm that produced the Iowa-Wisconsin hail and EF2 tornado on 4-5 Sep 2012. The storm was hail producing during this time frame and is identified with a white arrow. Above-anvil cirrus plumes from the storm of interest and another severe storm to the north are identified with red arrows. The color table corresponding to the BT color enhancement is provided along the bottom. No visible image was provided for (d) because of insufficient solar illumination.

\section{Discussion}

Trends in the storm minimum BT time series were well correlated with variations in total lightning, especially for the Wisconsin tornado event. Under the assumption that the timing of severe weather reports is accurate, all five of the severe hail events and the wind event described above occurred near to or shortly after a period of cloudtop warming. While one cannot assume a direct causeeffect relationship between the apparent updraft decay inferred from cloud-top signals and severe weather events, it is possible that the updraft decay allowed hailstones or damaging winds to descend to the surface. In contrast, the EF2 tornado occurred at the peak of a periodic oscillation in BT and the two lightning datasets provided the only indication of a significant change in storm internal dynamics. The BT oscillation at the time of the tornado appeared to be very similar to the previous three oscillations when no severe weather was reported; thus, GOES BT trends alone would not have added value to the warning decision-making process. On the other hand, the NALMA and/or ENTLN observed a lightning jump prior to the Wisconsin tornado, Pierce City and Marquette hailstorms, and Fairview wind event, highlighting the value of total lightning and future GOES-R GLM observations for recognition of impending severe weather.

The coarse spatial resolution of the BT imagery made subjective detection of cloud-top trends a challenge. Qualitative analysis of animated SRSOR data often did not reveal much change in storm structure from image to image. Only in the minimum storm BT time series plots can one start to see relevant trends. Despite the coarse BT data, when OT signatures were evident in the visible channel and had an OT-anvil height differential near to or greater than $1 \mathrm{~km}$ (Fig. 3), they typically were also associated with distinct BT minima that were regularly detected by the GOES-R OT algorithm. OTs were detected during periods of increased lightning flash rates and detections typically ceased when the storm was in decay, indicating that this product could be used to identify hazardous and potentially electrically active convection in data-sparse regions. Visible imagery and the OT detection products indicate that an individual OT persisted without any interruption for over $30 \mathrm{~min}$ within the two Alabama storms and the Pierce City hailstorm, so OTs are not always short-lived phenomena.

OT shadow-derived heights indicate that the Alabama storms reached a height of $18 \mathrm{~km}$ and their height trends generally agreed with BT trends for the two Alabama storms, indicating that BTs are usually representative of cloud-top height. Though the OT heights could not be validated, they were persistently above the 18.5-dBZ echo tops, which makes sense in that the 

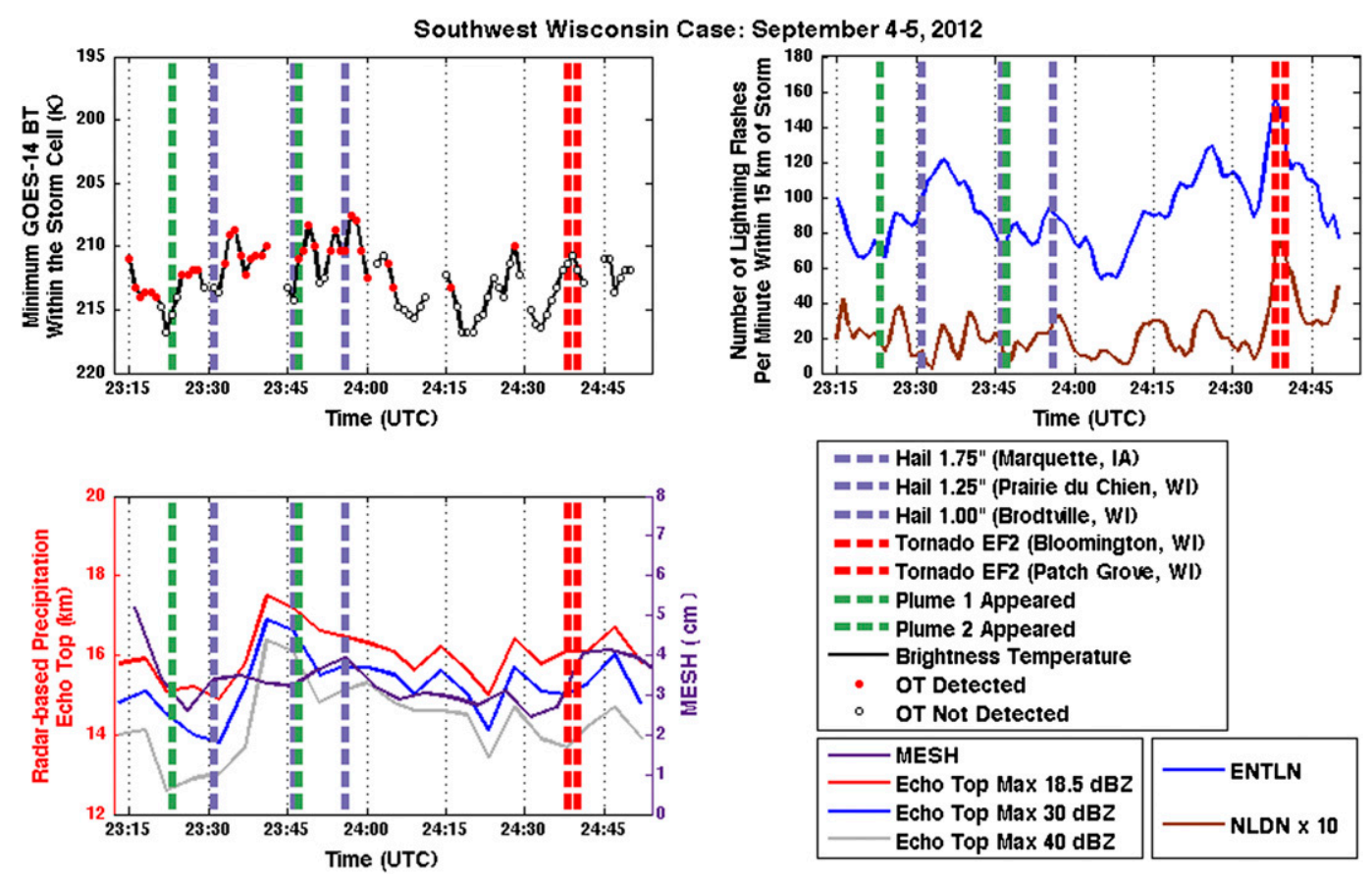

FIG. 11. As in Fig. 4, but for the storm that produced a series of severe hail events along the Iowa-Wisconsin border region and an EF2 tornado in Wisconsin on 4-5 Sep. NALMA data are not available over this region.

visible imagery depicts small ice particles at the physical cloud top that cannot be observed by the WSR-88D. The coldest BT in Alabama storm 1 was not coincident with an OT height peak, though a gap in SRSOR imagery occurred near the time of the coldest BTs for both Alabama storms, so this coupled with coarse IR resolution induces uncertainty regarding the relationship between the physical cloud top and the IR radiative top.

The radar echo tops and MESH offered some value and insight into storm updraft intensity. The 5-6-min radar products appeared quite coarse temporally relative to the SRSOR and lightning datasets and the echo tops often did not vary notably prior to many of the severe weather reports. A steady increase in the $40-\mathrm{dBZ}$ echo top indicated that the updraft remained strong as lightning flash activity increased prior to the Fairview wind event, a signal not present in the 18.5- and 30-dBZ echo tops. The echo tops from all three reflectivity levels and MESH were very well correlated for the Gorham hailstorm and southwestern Wisconsin severe events and these generally agreed with BT trends. Vertically integrated liquid (VIL) was also analyzed for these cases and was not considered to be very useful; thus, the dataset was not included in this paper. VIL reached its peak $\left(80 \mathrm{~kg} \mathrm{~m}^{-2}\right)$ for almost the entire lifetime of the Gorham, Pierce City, and southwestern Wisconsin storms, which simply indicated the presence of a vigorous storm. VIL was not well correlated with any of the other fields for the Alabama storms and did not show any signal near the time of the severe wind report.

Total lightning flash rates increased near the time of severe weather for four of the seven severe weather events. Using ENTLN as the basis for comparison across all cases, the most notable flash-rate increase occurred at the time of the EF2 tornadoes. The most anomalous case was the Gorham hailstorm where lightning activity was relatively constant for a lengthy period and then activity dropped significantly prior to the hail report. The trends in the ENTLN time series generally agreed quite well with those from NLDN except for 1) the Pierce City hailstorm where NLDN flash rates remained constant while ENTLN increased and 2) the Fairview wind event where the ENTLN flash rate increased at a greater rate than NLDN.

Above-anvil cirrus plumes appeared during or shortly after periods of relatively rapid cloud-top cooling $[\sim 5 \mathrm{~K}$ $\left.(5 \mathrm{~min})^{-1}\right]$. Though cloud-top cooling of equal or greater magnitude occurred at other points during the storm lifetimes, three of the four plumes appeared near to times when the BT was coldest and echo tops peaked, suggestive of ice injection at very high altitudes where thermodynamic conditions allowed the plume to persist. Given that the plumes tended to appear at peak storm vertical extent and likely peak updraft intensity, it is not all that surprising that severe weather would occur near to the time of plume appearance. Even though plumeproducing storms are quite rare relative to severe storms 
without plumes, the $9 \mathrm{~min}$ of additional lead time and $37 \%$ greater detection rate provided by SRSOR data further highlights the value of early plume recognition for severe storm nowcasting.

The results of this study indicate that time series of quantitative information derived from SRSOR data can indicate a hazardous storm, but the question remains as to how these time series could be generated for operational use. ABI will better observe convective cloud tops than current GOES, but it would be nearly impossible for a forecaster to manually interrogate every storm in widespread outbreaks when ABI is operating in super rapid scan mode. An automated data fusion framework like those described by Bedka et al. (2009) and Cintineo et al. (2013) could be used to derive multidataset time series for individual storm cells. Storm "objects" could be defined by a dataset with high temporal resolution in which the storm core remains temporally coherent throughout the storm life cycle. Examples of such datasets include radar reflectivity at a specific temperature threshold such as $-10^{\circ} \mathrm{C}$ (Lakshmanan and Smith 2009) or total lightning flash detections from lightning mapping arrays or the GOES-R GLM. Other satellite, radar, and numerical weather prediction model fields within each object could then be recorded and displayed to a forecaster.

\section{Summary}

This paper compared total and CG lightning, WSR$88 \mathrm{D}$, and $G O E S-14$ super rapid scan observations and derived products within deep convection during the 2012 SRSOR period. Five storms across the central and southeastern United States were monitored and each storm had a complex evolution but some commonalities were observed. The severe hail and wind cases occurred near to or shortly after relatively rapid cloud-top warming, indicating updraft decay that could have triggered a severe downdraft or allowed large hail to fall to the surface. Echo-top heights generally agreed with BT trends, though the 5-6-min radar scan frequency was insufficient to resolve high-frequency variations depicted by the 1-min datasets. OTs were frequently detected during each storm's lifetime, typically when the storm had greater echo-top heights and total lightning flash rates. Total lightning flash rates exhibited a relative maximum near to the time of five of the seven severe weather reports. The time trend of flash rates also increased sharply prior to these events, which is consistent with previous studies that identified the lightning jump signature as a severe weather precursor.

Above-anvil cirrus plumes appeared during or shortly after periods of relatively rapid cloud-top cooling and some occurred near to times with the coldest IR temperature and peak echo tops. Plumes indicated a severe storm for $57 \%$ of the plume events. This is considered a conservative estimate of the true plume-severe weather relationship because of known biases in severe weather reporting. Plumes appeared in SRSOR imagery $18 \mathrm{~min}$ ahead of severe weather reports on average and offered lead time for the $85 \%$ of severe weather events. SRSOR data provided an additional 9 min of lead time and $37 \%$ improvement in plume detection relative to what would be provided by GOES operational 15-30-min scanning. This is the first time that the above-anvil cirrus plume signature has demonstrated potential value for severe weather nowcasting over the United States, though more research is needed to better quantify plume-severe weather relationships and operational forecasting utility.

While operational 15-30-min GOES data have been proven to be quite useful for general convective storm monitoring, this and other previous studies show that key details of convective storm evolution are best depicted in SRSOR imagery. With the improvement in ABI spatial resolution relative to the current GOES Imager, we expect that severe weather indicators will become much more prominent, improving forecaster situational awareness and increasing the contribution of satellite data within the severe weather warning process. This study only scratches the surface regarding unraveling the complex processes occurring within and at the top of deep convective clouds observed at high temporal resolution by satellite, radar, and total lightning sensors. The study highlights some possibilities for using these datasets to improve convective storm nowcasting but definite conclusions cannot be drawn from just the five storms described here. More cases should be examined, especially from the 2013 (Schmit et al. 2015) and 2014 SRSOR periods, to confirm and expand upon these results.

Acknowledgments. This research has been supported by the GOES-R Risk Reduction Research (R3) program. In particular, we thank Dr. Steven Goodman, senior (chief) scientist, GOES-R System Program, for his guidance and support throughout this effort. The authors would also like to thank Tim Schmit (NOAA/NESDIS) and Martin Setvák (CHMI) for their valuable comments on this work. An additional thank you goes to NOAA/ NESDIS for collecting the GOES-14 SRSOR data.

\section{REFERENCES}

Achtor, T., T. Rink, R. Whittaker, D. Parker, and D. Santek, 2008: McIDAS-V: A powerful data analysis and visualization tool for multi and hyperspectral environmental satellite data. Atmospheric and Environmental Remote Sensing Data Processing and Utilization IV: Readiness for GEOSS II, M. D. Goldberg 
et al., Eds. International Society for Optical Engineering (SPIE Proceedings, Vol. 7085), 708509, doi:10.1117/12.795223.

Bedka, K. M., W. F. Feltz, J. Sieglaff, R. Rabin, M. J. Pavolonis, and J. C. Brunner, 2009: Toward an end-to-end satellite-based convective nowcasting system. Preprints, 16th Conf. on Satellite Meteorology and Oceanography/Fifth Annual Symp. on Future Operational Environmental Satellite SystemsNPOESS and GOES-R, Phoenix, AZ, Amer. Meteor. Soc., J15.2. [Available online at https://ams.confex.com/ams/pdfpapers/ 149265.pdf.]

— J. J. Brunner, R. Dworak, W. Feltz, J. Otkin, and T. Greenwald, 2010: Objective satellite-based overshooting top detection using infrared window channel brightness temperature gradients. J. Appl. Meteor. Climatol., 49, 181-202, doi:10.1175/ 2009JAMC2286.1.

Boccippio, D. J., K. L. Cummins, H. J. Christian, and S. J. Goodman, 2001: Combined satellite- and surface-based estimates of the intracloud-cloud-to-ground lightning ratio over the continental United States. Mon. Wea. Rev., 129, 108-122, doi:10.1175/ 1520-0493(2001)129<0108:CSASBE > 2.0.CO;2.

Bruning, E. C., and D. R. MacGorman, 2013: Theory and observations of controls on lightning flash size spectra. J. Atmos. Sci., 70, 4012-4029, doi:10.1175/JAS-D-12-0289.1.

Brunner, J. C., S. A. Ackerman, A. S. Bachmeier, and R. M. Rabin, 2007: A quantitative analysis of the enhanced- $V$ feature in relation to severe weather. Wea. Forecasting, 22, 853-872, doi:10.1175/WAF1022.1.

Cecil, D. J., 2009: Passive microwave brightness temperatures as proxies for hailstorms. J. Appl. Meteor. Climatol., 48, 12811286, doi:10.1175/2009JAMC2125.1.

Christian, H. J., R. J. Blakeslee, and S. J. Goodman, 1992: Lightning Imaging Sensor (LIS) for the Earth Observing System. NASA TM-4350, 44 pp. [Available from Center for Aerospace Information, P.O. Box 8757, Baltimore-Washington International Airport, Baltimore, MD 21240.]

Cintineo, J. L., T. M. Smith, V. Lakshmanan, H. E. Brooks, and K. L. Ortega, 2012: An objective high-resolution hail climatology of the contiguous United States. Wea. Forecasting, 27, 1235-1248, doi:10.1175/WAF-D-11-00151.1.

—, M. J. Pavolonis, J. M. Sieglaff, and A. K. Heidinger, 2013: Evolution of severe and nonsevere convection inferred from GOES-derived cloud properties. J. Appl. Meteor. Climatol., 52, 2009-2023, doi:10.1175/JAMC-D-12-0330.1.

Cummins, K. L., M. J. Murphy, E. A. Bardo, W. L. Hiscox, R. B. Pyle, and A. E. Pifer, 1998: A combined TOA/MDF technology upgrade of the U.S. National Lightning Detection Network. J. Geophys. Res., 103, 9035-9044, doi:10.1029/98JD00153.

Dobur, J. C., 2005: A comparison of severe thunderstorm warning verification statistics and population density within the NWS Atlanta county warning area. Preprints, Fourth Annual Southeast Severe Storms Symp., Starkville, MS, East Mississippi Chapter National Weather Association/Amer. Meteor. Soc., D2-6.

Dworak, R., K. M. Bedka, J. Brunner, and W. Feltz, 2012: Comparison between GOES-12 overshooting top detections, WSR-88D radar reflectivity, and severe storm reports. Wea. Forecasting, 27, 684-699, doi:10.1175/WAF-D-11-00070.1.

Goodman, S. J., and Coauthors, 2005: The North Alabama Lightning Mapping Array: Recent severe storm observations and future prospects. Atmos. Res., 76, 423-437, doi:10.1016/ j.atmosres.2004.11.035.

_ , and Coauthors, 2013: The GOES-R Geostationary Lightning Mapper (GLM). Atmos. Res., 125-126, 34-49, doi:10.1016/ j.atmosres.2013.01.006.
Hasler, A. F., J. Strong, R. H. Woodward, and H. Pierce, 1991: Automatic analysis of stereoscopic satellite image pairs for determination of cloud-top height and structure. J. Appl. Meteor., 30, 257-281, doi:10.1175/1520-0450(1991)030<0257: AAOSSI $>2.0 . \mathrm{CO} ; 2$.

Hillger, D., and Coauthors, 2013: First-light imagery from Suomi NPP VIIRS. Bull. Amer. Meteor. Soc., 94, 1019-1029, doi:10.1175/BAMS-D-12-00097.1.

Kanak, J., K. M. Bedka, and A. Sokol, 2012: Mature convective storms and their overshooting tops over central EuropeOvershooting top height analysis for summers 2009-2011. 2012 EUMETSAT Meteorological Satellite Conf., Sopot, Poland, EUMETSAT. [Available online at https://www.eumetsat. int $/$ website $/ \mathrm{wcm} / \mathrm{idc} / \mathrm{idcplg}$ ?IdcService $=$ GET_FILE \&dDoc Name $=$ PDF_CONF_P61_S7_12_KANAK_V\&RevisionSelection Method $=$ LatestReleased\&Rendition $=$ Web.]

Lakshmanan, V., and T. Smith, 2009: Data mining storm attributes from spatial grids. J. Atmos. Oceanic Technol., 26, 2353-2365, doi:10.1175/2009JTECHA1257.1.

Lazzara, M. A., and Coauthors, 1999: The Man computer Interactive Data Access System: 25 years of interactive processing. Bull. Amer. Meteor. Soc., 80, 271-284, doi:10.1175/ 1520-0477(1999)080<0271:TMCIDA > 2.0.CO;2.

Levizzani, V., and M. Setvák, 1996: Multispectral, high-resolution satellite observations of plumes on top of convective storms. J. Atmos. Sci., 53, 361-369, doi:10.1175/1520-0469(1996)053<0361: MHRSOO $>2.0 . \mathrm{CO} ; 2$.

Liu, C., and S. Heckman, 2010: The application of total lightning detection and cell tracking for severe weather prediction. TECO-2010-WMO Technical Conf. on Meteor. and Environmental Instruments and Methods of Observation, Helsinki, Finland, WMO. [Available online at https:/www.wmo.int/pages/ prog/www/IMOP/publications/IOM-104_TECO-2010/P2_7_ Heckman_USA.pdf.]

MacGorman, D. R., D. W. Burgess, V. Mazur, W. D. Rust, W. L. Taylor, and B. C. Johnson, 1989: Lightning rates relative to tornadic storm evolution on 22 May 1981. J. Atmos. Sci., 46, 221-250, doi:10.1175/1520-0469(1989)046<0221: LRRTTS > 2.0.CO;2.

McCann, D. W., 1983: The enhanced-V: A satellite observable severe storm signature. Mon. Wea. Rev., 111, 887-894, doi:10.1175/1520-0493(1983)111<0887:TEVASO >2.0.CO;2.

McCaul, E. W., J. Bailey, S. J. Goodman, R. Blakeslee, and D. E. Buechler, 2005: A flash clustering algorithm for North Alabama Lightning Mapping Array data. Preprints, Conf. on Meteorological Applications of Lightning Data, San Diego, CA, Amer. Meteor. Soc., 5.3. [Available online at https://ams. confex.com/ams/pdfpapers/84373.pdf.]

_, S. J. Goodman, K. M. LaCasse, and D. J. Cecil, 2009: Forecasting lightning threat using cloud-resolving model simulations. Wea. Forecasting, 24, 709-729, doi:10.1175/ 2008WAF2222152.1.

Orville, R. E., 2008: Development of the National Lightning Detection Network. Bull. Amer. Meteor. Soc., 89, 180-190, doi:10.1175/BAMS-89-2-180.

Rienecker, M. M., and Coauthors, 2011: MERRA: NASA's Modern-Era Retrospective Analysis for Research and Applications. J. Climate, 24, 3624-3648, doi:10.1175/ JCLI-D-11-00015.1.

Schmit, T. J., M. M. Gunshor, W. P. Menzel, J. J. Gurka, J. Li, and A. S. Bachmeier, 2005: Introducing the next-generation Advanced Baseline Imager on GOES-R. Bull. Amer. Meteor. Soc., 86, 1079-1096, doi:10.1175/BAMS-86-8-1079. 
, and Coauthors, 2014: GOES-14 Super Rapid Scan Operations to prepare for GOES-R. J. Appl. Remote Sens., 7, 073462, doi:10.1117/1.JRS.7.073462.

_ _ and Coauthors, 2015: Rapid Refresh information of significant events: Preparing users for the next generation of geostationary operational satellites. Bull. Amer. Meteor. Soc., doi:10.1175/ BAMS-D-13-00210.1, in press.

Schultz, C. J., W. A. Petersen, and L. D. Carey, 2009: Preliminary development and evaluation of lightning jump algorithms for the real-time detection of severe weather. J. Appl. Meteor. Climatol., 48, 2543-2563, doi:10.1175/ 2009JAMC2237.1.

_, — - and ——, 2011: Lightning and severe weather: A comparison between total and cloud-to-ground lightning trends. Wea. Forecasting, 26, 744-755, doi:10.1175/ WAF-D-10-05026.1.
Setvák, M., and Coauthors, 2010: Satellite-observed cold-ringshaped features atop deep convective clouds. Atmos. Res., 97, 80-96, doi:10.1016/j.atmosres.2010.03.009.

Thompson, K. B., M. G. Bateman, and L. D. Carey, 2014: A comparison of two ground-based lightning detection networks against the satellite-based Lightning Imaging Sensor (LIS). J. Atmos. Oceanic Technol., 31, 2191-2205, doi:10.1175/ JTECH-D-13-00186.1.

Williams, E. R., M. E. Weber, and R. E. Orville, 1989: The relationship between lightning type and convective state of thunderclouds. J. Geophys. Res., 94, 13 213-13 220, doi:10.1029/ JD094iD11p13213.

Witt, A., M. D. Eilts, G. J. Stumpf, J. T. Johnson, E. D. W. Mitchell, and K. W. Thomas, 1998: An enhanced hail detection algorithm for the WSR-88D. Wea. Forecasting, 13, 286-30, doi:10.1175/ 1520-0434(1998)013<0286:AEHDAF>2.0.CO;2. 